\title{
UMTRA TECHNICAL AsSISTANCE CONTRACTOR QUALITY Assurance Program Plan
}

\section{October 1994}

\section{DISCLAIMER}

This report was prepared as an account of work sponsored by an agency of the United States Government. Neither the United States Government nor any agency thereof, nor any of their employees, makes any warranty, express or implied, or assumes any legal liability or responsibility for the accuracy, completeness, or usefulness of any information, apparatus, product, or process disclosed, or represents that its use would not infringe privately owned rights. Reference herein to any specific commercial product, process, or service by trade name, trademark, manufacturer, or otherwise does not necessarily constitute or imply its endorsement, recommendation, or favoring by the United States Government or any agency thereof. The views and opinions of authors expressed berein do not necessarily state or reflect those of the United States Government or any agency thereof. 


\section{DISCLAIMER}

Portions of this document may be illegible in electronic image products. Images are produced from the best available original document. 
UMTRA TECHNICAL ASSISTANCE CONTRACTOR QUALITY ASSURANCE PROGRAM PLAN

October 1994 
APPROVALS

UMTRA TECHNICAL ASSISTANCE CONTRACTOR QUALITY ASSURANCE PROGRAM PLAN

CONTRACT NO. DE-AC0491AL62350

REVISION

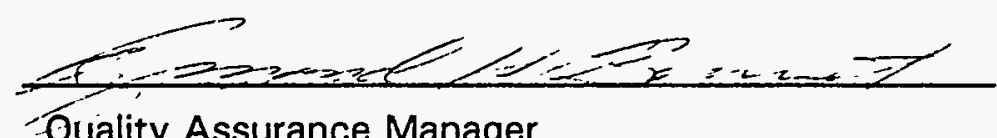

- Quality Assurance Manager

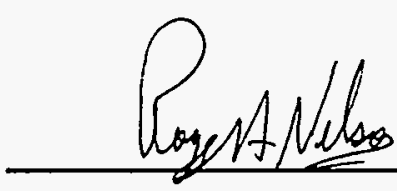

Project Manager
October 1994

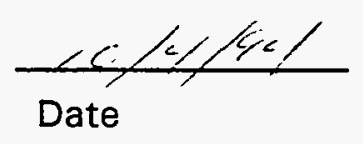

$\frac{10 / 4 / 94}{\text { Date }}$ 


\section{UMTRA TECHNICAL ASSISTANCE CONTRACTOR QUALITY ASSURANCE PROGRAM PLAN \\ RECORD OF REVISIONS}

\begin{tabular}{|c|c|c|c|}
\hline REVISION NO. & SECTION & REVISED PAGE NO(S). & DATE REVISED \\
\hline 1 & $\ldots . T$ & REVISION.... & $04 / 19 / 85$ \\
\hline 2 & $\ldots . T$ & REVISION.... & $01 / 22 / 86$ \\
\hline 3 & $\ldots . T$ & REVISION.... & $06 / 04 / 92$ \\
\hline 4 & $\ldots . T$ & REVISION.... & $10 / 29 / 93$ \\
\hline 茨 & : & REVSSON & $10 \% 03 / 94$ \\
\hline
\end{tabular}

The Quality Assurance Program Plan was revised effective October 1994.

Revision 3 performed by Paul Pehrson, Sr. QA Specialist - TAC. 


\section{TABLE OF CONTENTS}

Section

Page

UMTRA TECHNICAL ASSISTANCE CONTRACTOR

QUALITY ASSURANCE POLICY

vii

FOREWORD $\ldots \ldots \ldots \ldots \ldots \ldots \ldots \ldots \ldots \ldots \ldots \ldots \ldots \ldots \ldots \ldots \ldots \ldots$

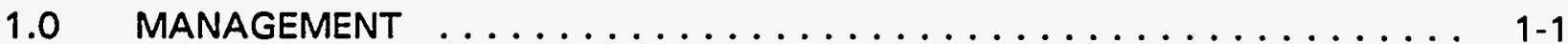

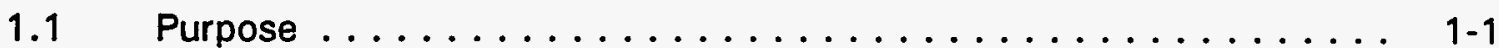

1.2 General . . . . . . . . . . . . . . . . . . . . . $1-1$

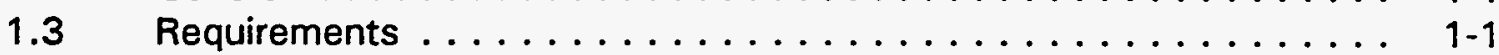

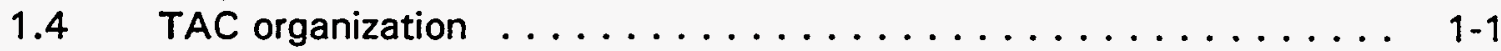

1.4.1 TAC Project Manager .................. 1-1

1.4 .2 Site Management ................... 1-3

1.4 .3 Technical Services ................... 1-3

1.4.4 Management Services .................. 1-5

1.4.5 TAC QA Department manager .............. 1-5

1.4.6 TAC QA specialist ................... 1-6

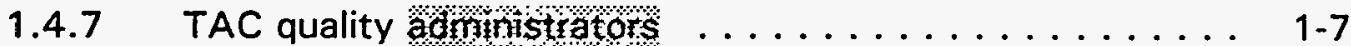

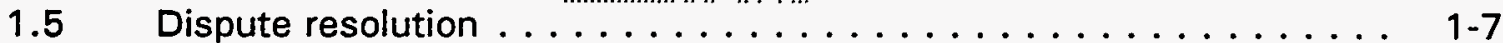

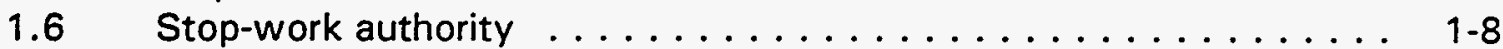

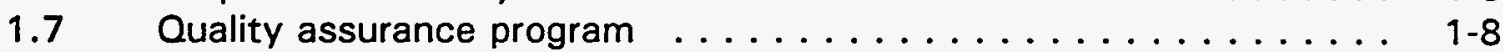

2.0 PERSONNEL TRAINING AND QUALIFICATIONS ............. $2-1$

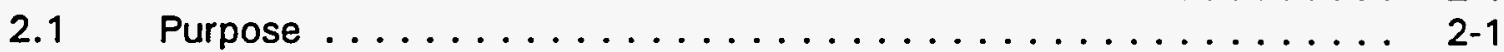

$2.2 \quad$ General ............................ $2-1$

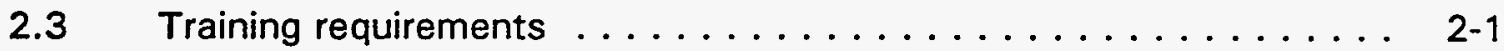

2.4 Proficiency evaluation ..................... $2-2$

2.5 Documentation/records ...................... $2-2$

2.6 Verification of implementation ................ $2-2$

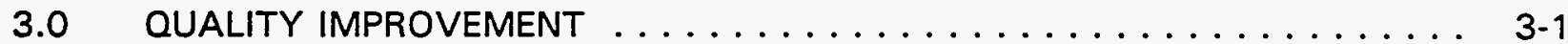

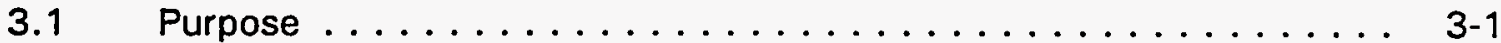

3.2 Quality improvement ..................... 3-1

3.3 Nonconformances . . . . . . . . . . . . . . . . . . . $3-2$

3.4 Corrective action ...................... $3-5$

3.5 Adverse conditions identified by the UMTRA Project Office . . . . . 3-8

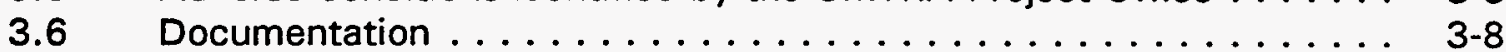

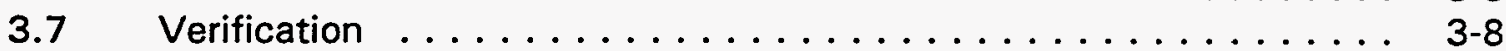

4.0 DOCUMENTS AND RECORDS $\ldots \ldots \ldots \ldots \ldots \ldots \ldots \ldots \ldots \ldots$

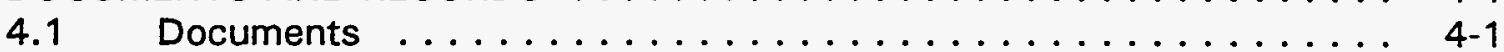

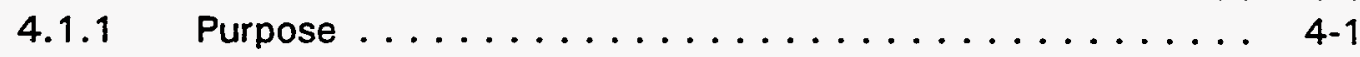

$4.1 .2 \quad$ General ........................ 4-1

4.1.3 Document preparation, revision, review, and approval ... 4-1

4.1 .4 Issuance and distribution ............... 4-2 
TABLE OF CONTENTS (Continued)

Section

Page

4.1.5 Controlled documents ................. 4-2

4.1 .6 Document changes .................. 4-2

4.1.7 Implementing requirements .............. 4-3

4.2 Records ............................ 4.3

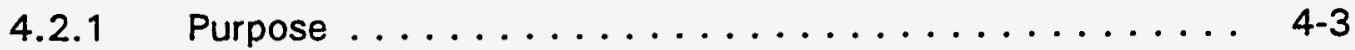

4.2.2 General ........................ 4-3

4.2.3 Records requirements ................. 4-3

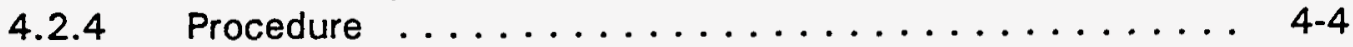

$4.2 .5 \quad$ Records filing . . . . . . . . . . . . . . . . 4 4-4

4.2.6 Record storage .................. 4 4 .5

4.2.7 Corrected information in records . . . . . . . . . . 4 4-5

4.2 .8 Disposition ...................... 4 4-5

4.2.9 UMTRA Project document control system . . . . . . . . 4-5

4.2.10 Records system .................... 4-5

4.3 Verification of implementation $\ldots \ldots \ldots \ldots \ldots \ldots \ldots \ldots \ldots$

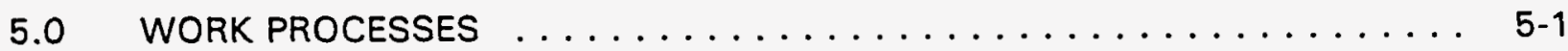

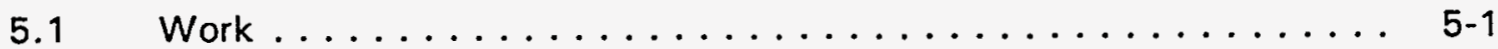

$5.1 .1 \quad$ Purpose ..................... $5-1$

5.1 .2 Requirements ................... 5-1

5.1.3 Work processes, instructions, procedures, and drawings .. 5-1

5.1 .4 Quality responsibilities ................ 5-1

5.2 Identification and control of items . . . . . . . . . . . $5-2$

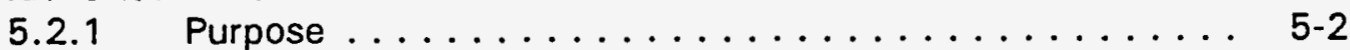

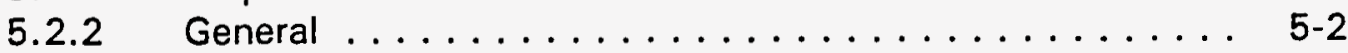

5.2 .3 Requirements .................... 5-2

5.2 .4 Procedures ...................... 5-3

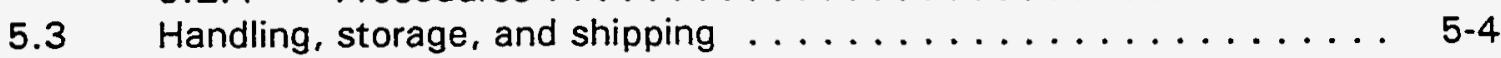

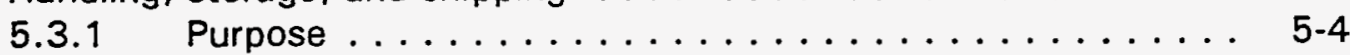

$5.3 .2 \quad$ General ........................ 5-4

5.3 .3 Requirements ..................... $5-4$

5.3 .4 Procedure ..................... 5-4

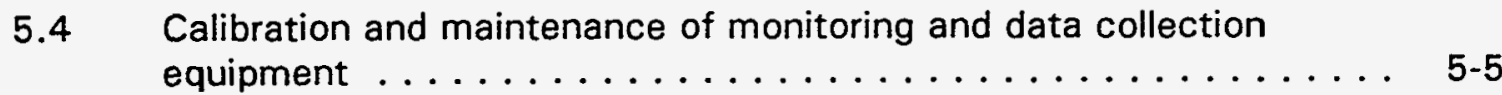

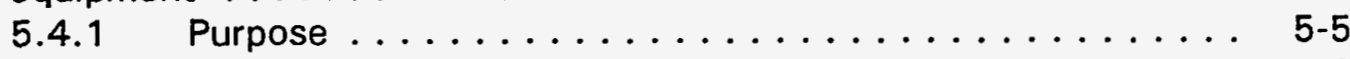

$5.4 .2 \quad$ General . . . . . . . . . . . . . . . . $5-6$

5.4 .3 Requirements .................... 5-6

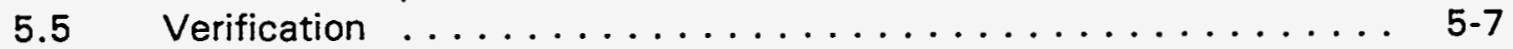

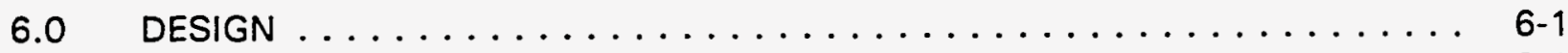

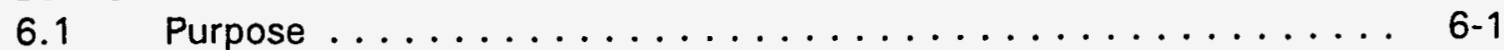

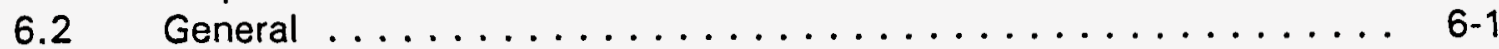

6.3 Requirements ....................... $6-1$ 
TABLE OF CONTENTS (Continued)

Section

Page

6.4 UMTRA Project Office control of design activities $\ldots \ldots \ldots \ldots$ 6-1

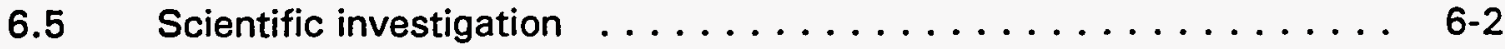

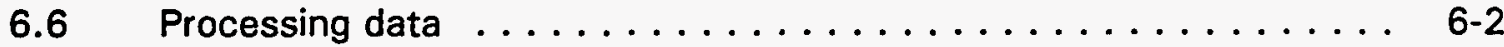

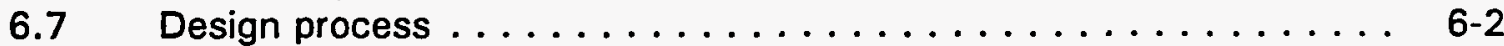

6.8 Design analysis . . . . . . . . . . . . . . . . . . . 6 6-3

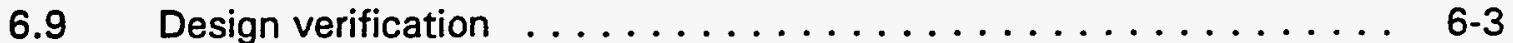

6.10 Design reviews . . . . . . . . . . . . . . . . . . . . 6.4

6.11 Computer software .......................... 6. 6.4

6.12 Readiness/on-board reviews for design activities .......... 6-4

6.13 Design change control ....................... 6-5

6.14 Design error and design deficiency control . . . . . . . . . . . 6-5

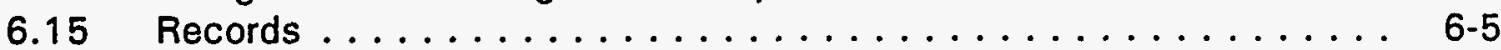

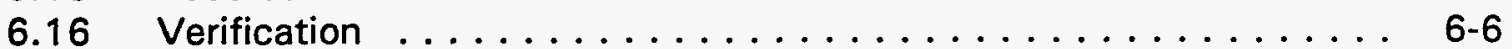

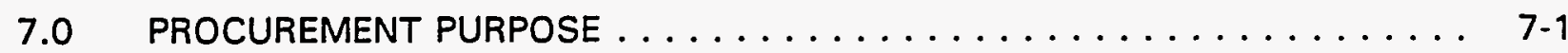

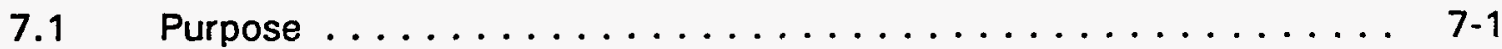

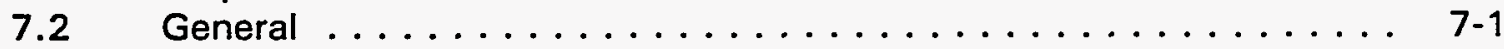

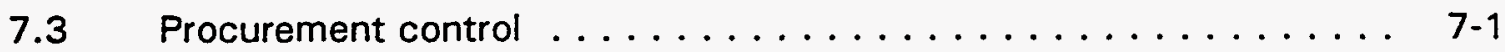

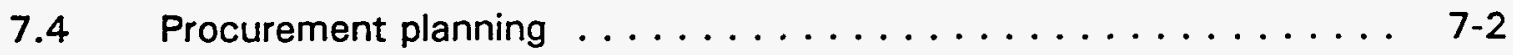

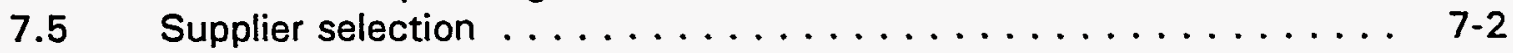

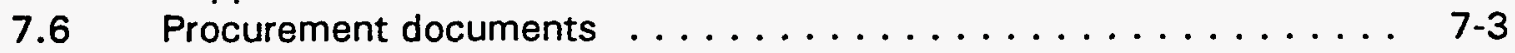

7.7 Supplier performance evaluation . . . . . . . . . . . . . $7-4$

7.8 Supplier-generated document control .............. $7-5$

7.9 Acceptance of materials, equipment, and services . . . . . . . 7-5

7.10 Nonconformances . . . . . . . . . . . . . . . . . . 7-6

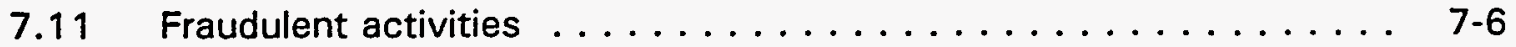

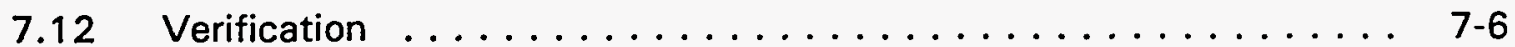

8.0 INSPECTION AND ACCEPTANCE TESTING $\ldots \ldots \ldots \ldots \ldots \ldots$

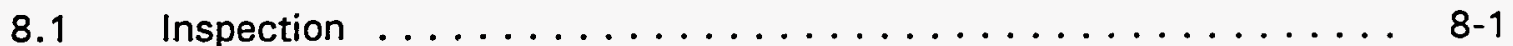

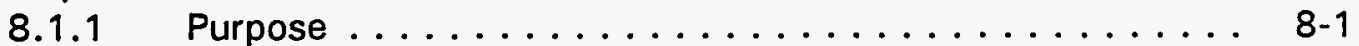

8.1 .2 General ..................... 8-1

8.1.3 Inspection procedures ................ 8-1

8.1 .4 Inspection personnel .................. 8-2

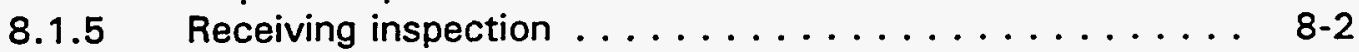

8.1 .6 Inspection records .................. 8-2

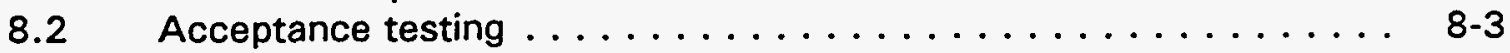

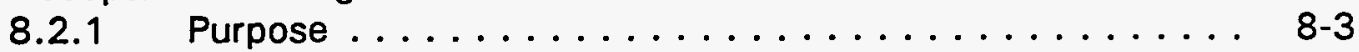

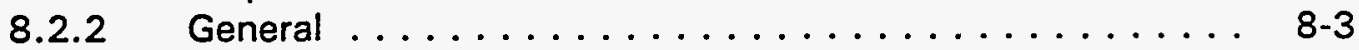

8.2.3 Requirements .................... 8-3

8.2.4 Acceptance testing ................. 8-3

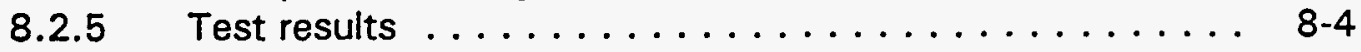

8.2 .6 Test records $\ldots \ldots \ldots \ldots \ldots \ldots \ldots \ldots \ldots \ldots . \ldots \ldots$ 


\section{TABLE OF CONTENTS (Continued)}

Section

Page

$8.3 \quad$ Measuring and test equipment $\ldots \ldots \ldots \ldots \ldots \ldots \ldots \ldots \ldots$

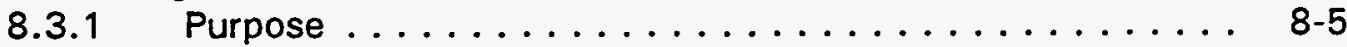

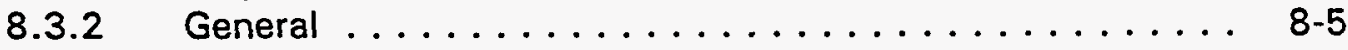

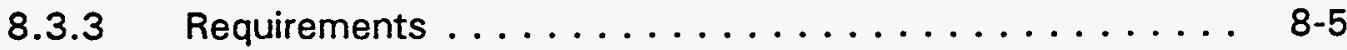

8.3 .4 Procedure ...................... 8 .6

8.3.5 Calibration standards . . . . . . . . . . . . . 8-6

8.3.6 Issuance of M\&TE .................. 8-7

8.4 Verification of implementation $\ldots \ldots \ldots \ldots \ldots \ldots \ldots \ldots \ldots$

9.0 MANAGEMENT ASSESSMENTS $\ldots \ldots \ldots \ldots \ldots \ldots \ldots \ldots \ldots \ldots \ldots$

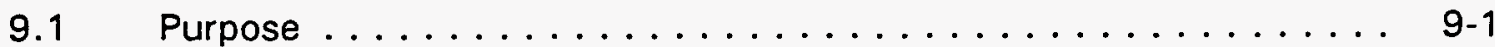

9.2 General .......................... $9-1$

9.3 Requirements ......................... $9-1$

9.4 Assessment purpose/results . . . . . . . . . . . . . 9 9-1

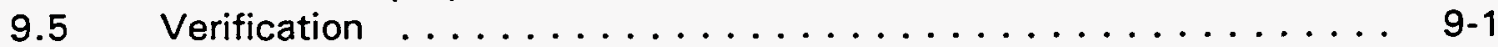

10.0 INDEPENDENT ASSESSMENTS $\ldots \ldots \ldots \ldots \ldots \ldots \ldots \ldots \ldots \ldots$

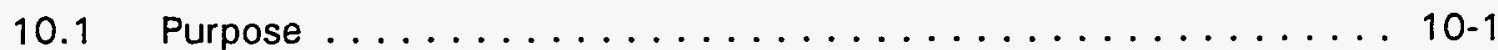

10.2 General ............................. 10 . . . . . .

10.3 Requirements ........................ 10-1

10.4 Scheduling ......................... 10-2

10.5 Audit personnel ....................... 10-3

10.6 Preaward evaluation ...................... 10-4

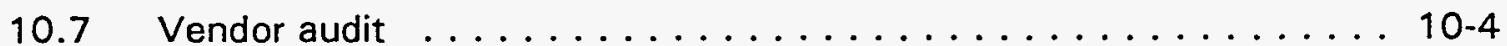

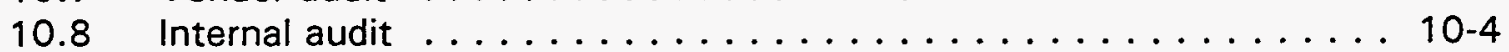

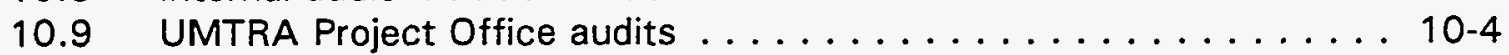

10.10 TAC supplemental audits . . . . . . . . . . . . . . . . 10.4

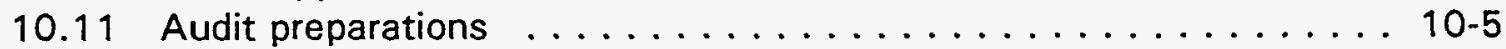

10.12 Audit performance ..................... 10.5

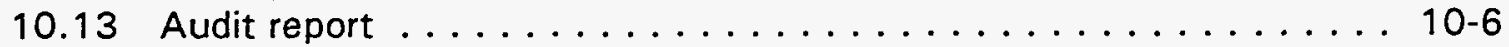

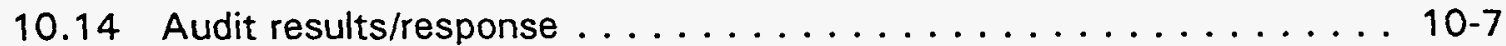

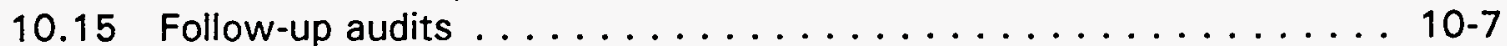

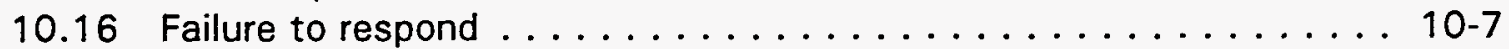

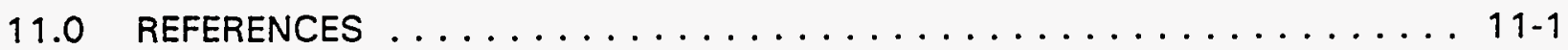

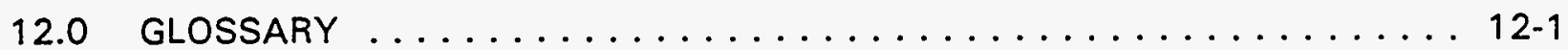




\section{LIST OF FIGURES}

Figure

Page

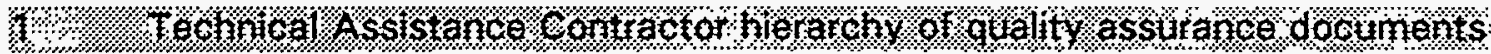

1.1 UMTRA Project Technical Assistance Contractor organization . . . . . . . . 1-2

3.1 Nonconformance Report $\ldots \ldots \ldots \ldots \ldots \ldots \ldots \ldots \ldots \ldots \ldots$

3.2 Deficiency/Nonconformance Report $\log \ldots \ldots \ldots \ldots \ldots \ldots \ldots$

3.3 Corrective Action Request . . . . . . . . . . . . . . . . 3-6

3.4 Corrective Action Request $\log \ldots \ldots \ldots \ldots \ldots \ldots \ldots \ldots \ldots$ 


\section{LIST OF ACRONYMS}

\section{Acronym Definition}

AL DOE-Albuquerque Office

AO Albuquerque Operations

APM assistant project managers

CARD Characterization and Remedial Design Department

CAR corrective action request

DCO data collection objectives

DOE U.S. Department of Energy

DQO data quality objectives

EH\&S environment, health, and safety

EML Environmental Measurements Laboratory

ER environmental restoration

GRS General Records Schedule

HO Headquarters

IPMS Integrated Project Management System

Th .2 .1 independent technical review

JEG Jacobs Engineering Group Inc.

LOE level of effort

M\&TE measuring and test equipment

NARA National Archives and Records Administration

NEPA National Environment Policy Act

NIST National Institute of Standards and Technology

NCR nonconformance reports

ORE operational readiness evaluation

PMCS Project Management Control System

PDCS Project Document Control System manual

$\mathrm{QA} \quad$ quality assurance

OAIP : $: 2$. Quafity Assurance Implementation Plan

QAP .8 .8 Ouality Assurance Program

QAPP Quality Assurance Program Plan

QC quality control

QIS quality improvement suggestion

RAC Remedial Action Contractor

SOP standard operating procedure

SPAM System for Performance Advancement Measurement

SPEAR Software Program for Environmental Analysis and Reporting

TAC Technical Assistance Contractor

TRAIN Training Records Administration and Information Network

TSGL Technical Support Group leader

UMTRA Uranium Mill Tailings Remedial Action

WSAP water sampling and analysis plan 


\section{UMTRA TECHNICAL ASSISTANCE CONTRACTOR QUALITY ASSURANCE POLICY}

Inherent in the quality of the Technical Assistance Contractor's (TAC) professional services is the capability to manage Project assignments so as to comply with their intended functions and to satisfy the client's expectations. These objectives must be accomplished in a manner that will meet or exceed performance standards, safety and environmental standards, and client contract requirements at a cost consistent with sound economic planning.

Quality assurance (QA) procedures and systems have been developed to ensure compliance with all engineering criteria, specifications, and codes. The quality programs to support this policy are intended to reach every TAC employee in all Project organizations. The implementation of the quality programs and procedures shall ensure the highest standards of performance. The TAC objectives of complete compliance with all regulatory, environment, safety, and health requirements will be strengthened by each employee's acceptance of responsibility for quality productivity.

The TAC applies a graded approach to QA, acknowledging that public health and safety are not always affected by remediation activities and that an adequate level of quality is also needed for operational reliability and maintainability. Applicable portions of this document shall be implemented to the maximum degree for quality-related functions that are identified as safety-related; a less stringent but still viable quality level shall be maintained for other project activities.

The OA manager shall have the responsibility and authority to implement procedures, provide training, and generate motivation to the extent required to maintain and control a uniform standard of professional service at predetermined high levels of quality.

Subcontract $/$ abojatories performing radiochemisthy analysis shall particlpate in the

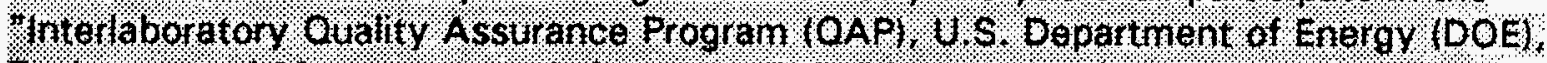
Environmental Measurements Laboratory (EML) I intercomparison study. Additonat Grtercomparis on studies for subcontract laboratories are discussed in section $7,7.5$ of this O.dility Assurance Program Plan (OAPP). 



\section{FOREWORD}

This Quality Assurance Program Plan (QAPP) provides the primary requirements for the integration of quality functions into all Technical Assistance Contractor (TAC) Project organization activities.

The QAPP is the written directive authorized by the TAC Program Manager to accomplish this task and to implement procedures that provide the controls and sound management practices needed to ensure TAC contractual obligations are met. The QA program is designed to use monitoring, audit, and surveillance functions as management tools to ensure that all Project organization functions are executed in a manner that will protect public health and safety, promote the success of the Project, and meet or exceed contract requirements.

The key to ensuring compliance with this directive is a two-step professional approach: utilize the quality system in all areas of activity, and generate a personal commitment from all personnel to provide quality service. The quality staff will be experienced, trained professionals capable of providing maximum flexibility to Project goal attainment. Such flexibility will enable the staff to be more cost effective and to further improve communication and coordination.

To provide control details, this QAPP will be supplemented by approved standard operating procedures that provide requirements for performing the various TAC quality-related activities. These procedures shall describe applicable design input and document control activities and documentation.

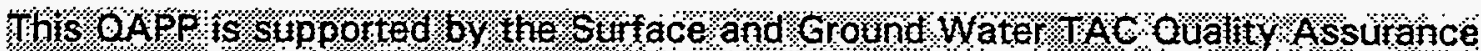

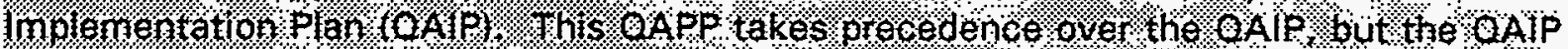

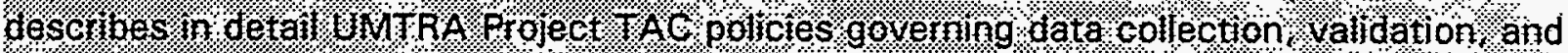

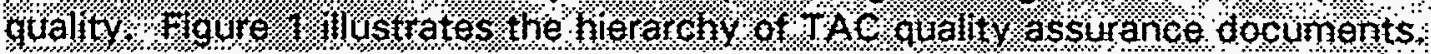

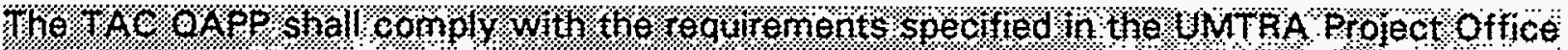

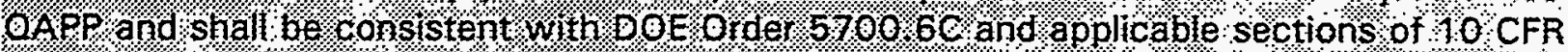

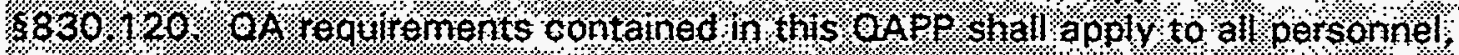
processes. and activities, including planing, scbedung and cost controt, foerformed fy the 180 ond is contractols.

The QA program shall be subject to periodic review and revision to encompass new standards and techniques. Its intent-to provide guidance toward the attainment of quality engineering and Project management services-shall not be de-emphasized or unilaterally waived. 


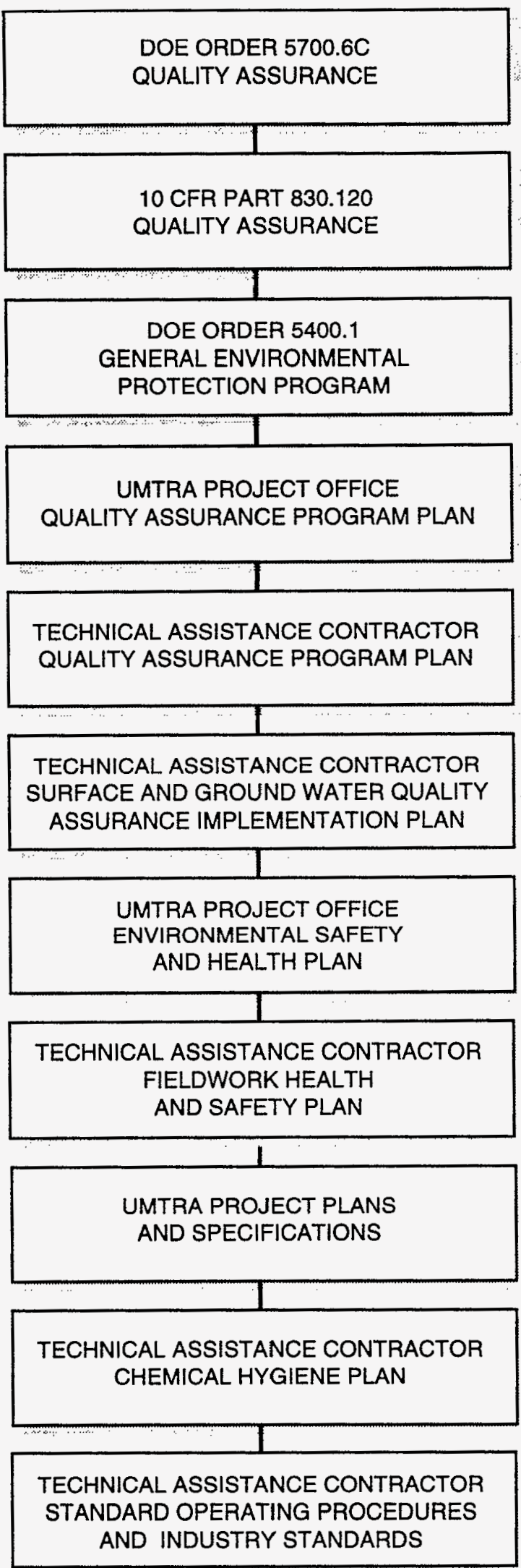

FIGURE 1

TECHNICAL ASSISTANCE CONTRACTOR HIERARCHY OF QUALITY ASSURANCE DOCUMENTS 


\subsection{MANAGEMENT}

\subsection{PURPOSE}

1.1.1 This section defines the Technical Assistance Contractor (TAC) organizations that perform activities affecting quality and describes the TAC quality assurance (QA) program. The organizational structure shall assign responsibility so that quality is achieved and maintained by the individuals and organizations that perform the work.

\subsection{GENERAL}

1.2.1 The TAC organizational structure and functional responsibilities are described in the following paragraphs.

1.2.2 The TAC is made up of the contract team: Jacobs Engineering Group Inc. (JEG); Geraghty \& Miller, Inc.; Roy F. Weston, Inc.; and Sergent, Hauskins \& Beckwith. The TAC is structured to provide adequate organizational autonomy for the OA function as the program TAC OA manager reports to the JEG Albuquerque Operations (AO) manager and to the JEG corporate $Q A$ organization. The TAC functional organization is illustrated in Figure 1.1.

\subsection{REQUIREMENTS}

1.3.1 Programmatic OA requirements are imposed by the U.S. Department of Energy (DOE) Uranium Mill Tailings Remedial Action (UMTRA) Project Office on the TAC through the issuance of the DOE Quality Assurance Program Plan (QAPP) (DOE, (994a).

1.4 TAC ORGANIZATION

\subsubsection{TAC Project Manager}

a. The TAC Project Manager shall be responsible for overseeing the overall effort of all TAC technical and administrative activities and interfaces with the UMTRA Project Manager and the TAC QA manager. The TAC Project Manager shall be responsible for organizing, administering, planning, budgeting, and coordinating the UMTRA TAC Project. Also, the TAC Project Manager shall be responsible for enforcing the $O A$ program and ensuring that the TAC staff members implement and comply with the applicable requirements of this QAPP and the TAC standard operating procedures (SOP). All site, department, and task managers shall report to the TAC Project Manager through assistant project managers (APM). 


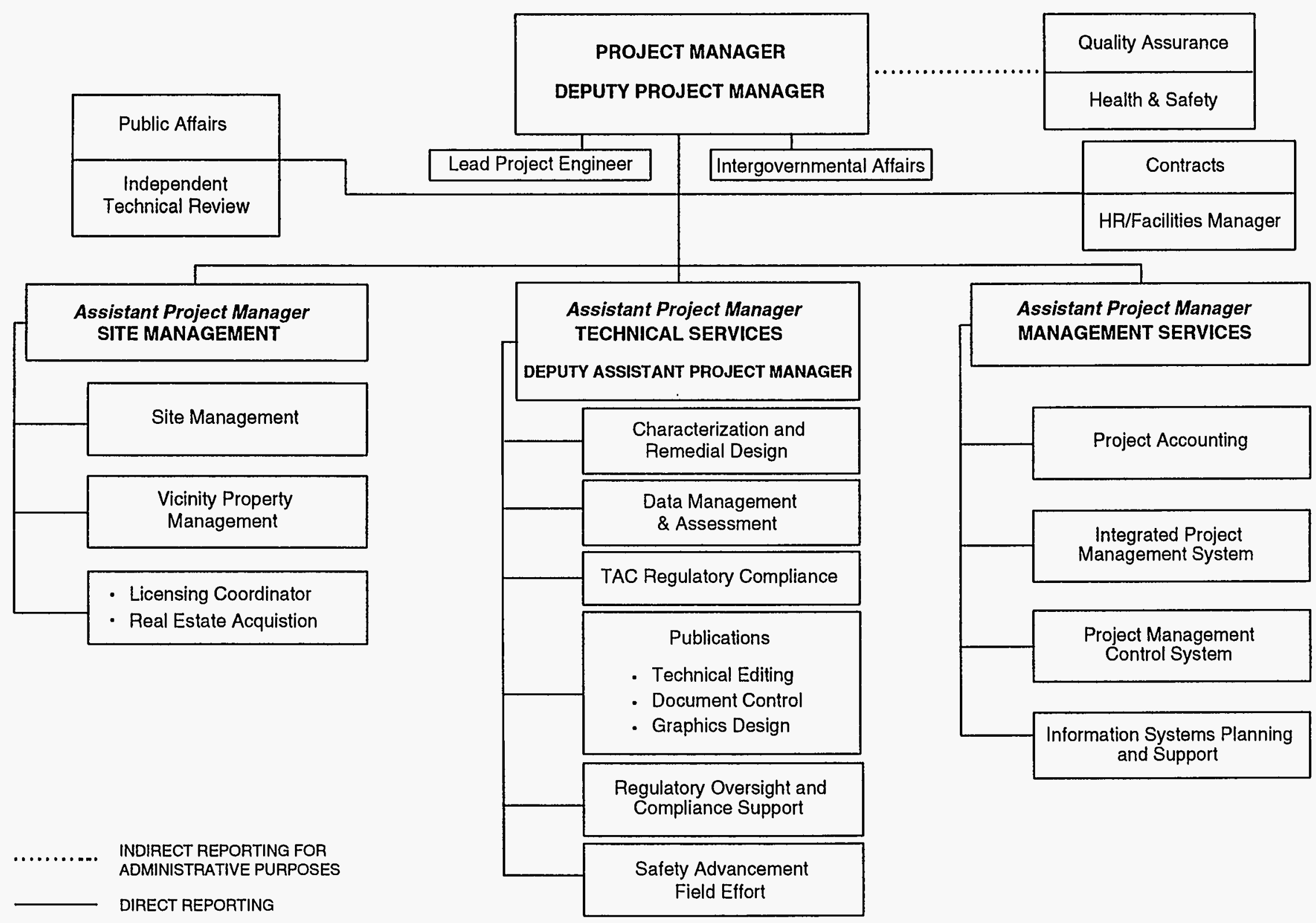

FIGURE 1.1

UMTRA PROJECT TECHNICAL ASSISTANCE CONTRACTOR ORGANIZATION 


\subsubsection{Site Management}

a. The Site Management Department shall integrate the capabilities of the UMTRA Project technical support groups into site-specific matrix teams that are responsible for remedial action technical design and the production of site-specific documents. Site Management is also the focal point of most Project-related issues and all site-specific issues, and resolves issues through the use of site matrix teams. A site matrix team consists of a site manager, representatives of the various technical groups, a cost/schedule engineer, and a representative of the Public Affairs Department. The site manager oversees site planning, baseline schedules, cost tracking, site remedial action planning, site status assessment, vicinity property management, and public information coordination. These activities involve regular interface with state and Federal agencies, tribal representatives, citizen groups, and the DOE.

\subsubsection{Technical Services}

a. The Technical Services Department shall include the Characterization and Remedial Design, Regulatory Compliance Services, and Data Management and Assessment Departments. The responsibilities of these departments are described below:

1. The Characterization and Remedial Design (CARD) Department shall provide technical expertise in the areas of engineering (geotechnical, civil, and process), hydrology, and health physics. The department is the focal point for the development of site characterization and remediation strategies for the groundwater program. The department also develops groundwater protection strategies and conceptual designs and performs design reviews for surface activities.

Departmental staff also conduct special studies of pertinent technical issues and provide technical position papers at the request of the Project Office.

2. The Regulatory Compliance Department shall be responsible for ensuring that the UMTRA Project is in compliance with applicable DOE, Federal, state, and local environmental regulations and guidance from the planning through implementation and licensing phases of remedial action. Compliance and verification of compliance shall be accomplished through research, field activities, analyses, and document preparation. The TAC Regulatory Compliance Department shall perform the following activities and shall provide technical support to ensure compliance is achieved throughout all phases of the UMTRA Project.

a. Conduct research, surveys, and analyses for preparation of National Environment Policy Act (NEPA) documentation during Project planning. 
b. Evaluate the applicability of environmental laws and regulations other than NEPA.

c. Plan and integrate permit and access activities for timely implementation of UMTRA Project site activities.

d. Perform health and safety, radiological, and environmental surveillance and audits at UMTRA Project sites during the implementation of remediation action.

e. Provide technical staff support to site licensing and long-term surveillance and maintenance planning.

f. Develop regulatory compliance procedures.

3. The Data Management and Assessment Department shall integrate the disciplines of risk assessment, geochemistry, data management, statistics, and water sampling to generate defensible environmental data, technically sound interpretations of the data, and interpretative documents, including risk assessments. These activities help in the selection of surface and groundwater remediation that protects human health and the environment.

a. Experienced toxicologists, geochemists, analytical chemists, ecologists, field geologists, and mathematicians shall perform a variety of activities, including the following:

1. Research and produce site-specific risk assessments.

2. Conduct ecological sampling in conjunction with the Regulatory Compliance Department.

3. Coordinate preparation of water sampling and analysis plans (WSAP) in conjunction with the Engineering and Design Department.

4. Prepare reports covering geochemical interpretation of ore materials, tailings, or water quality.

5. Conduct geochemical experiments to support Project needs.

6. Develop and use QA protocols associated with the Software Program for Environmental Analysis and Reporting (SPEAR) (DOE, 1992) water-quality data base.

7. Develop the TAC Technical Data Administration Plan. 
8. Develop the statement of work for subcontract analytical services.

\subsubsection{Management Services}

a. Management Services shall be composed of two major functional elements: the Integrated Project Management System (IPMS) and the Project Management Control System (PMCS).

b. The IPMS Group shall establish program baseline, total program cost and schedule reporting, cost and schedule change control, and Federal fiveyear budget planning. The IPMS group also shall be responsible for preparing and publishing the site-specific plan, site progress report, participants progress report, environmental restoration (ER) prioritization scoring system, project managers progress report, and other Project-level documents.

c. The PMCS Group shall perform detailed, site-specific, and level-of-effort (LOE) planning, scheduling, budgeting, accounting, performance measurement, cost and schedule variance analysis, cost and schedule change control, and system maintenance.

\subsubsection{TAC QA Department manager}

a. The TAC QA manager shall be responsible for overseeing and controlling all TAC QA activities in support of the UMTRA Project. The QA manager shall interface directly with the UMTRA Project Office QA manager and the TAC Project Manager.

b. The TAC QA manager shall have the authority to carry out the following responsibilities:

1. Support the UMTRA Project Office QA manager.

2. Develop and implement the TAC QA program.

3. Develop and organize the QA Department and administrative staff.

4. Establish and implement a QA training program.

5. Establish and implement audit and surveillance programs and schedules.

6. Review all TAC SOPs.

7. Evaluate the effectiveness of the QA program, report to TAC management, and establish and maintain interface with the TAC and UMTRA Project Office. 
8. Recommend to the TAC Project Manager that work be stopped when activities are not in compliance with contract documents or when unsatisfactory work is performed. Oral recommendations will be followed by written recommendations.

9. Establish plans and schedules and methods or coordination to ensure that $Q A$ procedures are followed.

10. Represent the TAC on Project $O A$ matters, in meetings, and in the resolution of QA problems.

11. Review deficiency reports, nonconformance reports (NCR), and corrective action reports.

12. Monitor QA personnel activities, schedules, assignments, and administrative details.

13. Perform quality trend analysis.

c. The TAC QA manager shall report to the JEG management level needed to ensure that the required authority and freedom to organize is provided for the following:

1. Access work areas to identify problems associated with quality requirements.

2. Initiate, recommend, or provide solutions for establishing corrective actions.

3. Verify implementation of corrective actions and solutions.

4. Perform duties independent of costs, schedules, and personnel considerations.

5. Ensure that processing, delivery, installation, or use of deficient material or workmanship is controlled until corrective action occurs.

\subsubsection{TAC QA specialist}

a. The TAC QA specialist shall report directly to the TAC OA manager and shall be responsible for the following:

1. Supporting the UMTRA Project Office OA manager in performing Project audits.

2. Implementing audit techniques and procedures. 
3. Developing audit schedules, selecting audit team members, and conducting audits under direction from the UMTRA Project Office QA manager.

4. Developing audit checklists and preparing audit reports.

5. Performing audit follow-up activities.

6. Maintaining records of audit activities.

7. Preparing and maintaining records of audits and an audit/surveillance tracking system.

b. Section 10.0, Independent Assessments, discusses methods for establishing and implementing independent assessments.

\subsubsection{TAC quality administrators}

a. The TAC quality animinstrator. shall report directly to the TAC QA manager and shall be responsible for the following:

1. Supporting the UMTRA Project Office OA manager in tracking and trending results from the Assessment and Analysis Documentation and Information Tracking System, System for Performance Advancement Measurement, and Training Records Administration and Information Network (TRAIN) programs.

2. Developing management reports on lessons learned from Root Cause Analysis Reports.

3. Using and identifying the benefits of data base management systems, tracking performance improvements, and identifying benefits.

4. Preparing reports for project management on performance improvements, and coordinating, participating, and conducting TOM training.

5. Supporting the quality council by tracking outstanding quality improvement suggestions (Q|S), developing correspondence, and maintaining records.

6. Supporting TAC internal $Q A$ audits.

\subsection{DISPUTE RESOLUTION}

1.5.1 All Project concerns and differences of opinion involving technical and quality issues presented at any management level shall be addressed to the managers at that level. If the issue or concern cannot be resolved, it will be presented 
progressively to the next management level up to the DOE-Albuquerque Office $(\mathrm{AL})$ of the manager.

\subsection{STOP-WORK AUTHORITY}

1.6.1 The overall authority to stop work on all levels of the UMTRA Project rests solely with the DOE contracting officer. The DOE Contracting Officer shall be fully informed by the DOE-AL UMTRA Project Manager, who is the contracting officer's representative. Direction to stop work can be issued by any DOE representative when imminent danger to personnel health and/or safety is involved.

1.6.2 Personnel responsible for issuing the stop work order shall, in all cases, notify the responsible supervisor or task manager, who in turn shall notify the next level of management, $\mathrm{QA}$, and health and safety personnel as necessary, and the UMTRA Project Office. The TAC OA manager shall assist the UMTRA Project Office in investigating all stop work orders to identify causes for the order and to bring adequate resolution to the problems. The UMTRA Project Manager shall be responsible for issuing orders to continue work.

\subsection{QUALITY ASSURANCE PROGRAM}

1.7.1 The UMTRA Project Office established and implemented the UMTRA Project QA program to control the quality of any activity, or portion thereof, that impacts public health and safety or the success of the Project. The TAC QA program shall comply with the requirements specified in the UMTRA Project Office QAPP and shall be consistent with DOE Order $5700.6 \mathrm{C}$ ard applictble sections of 10 EFR $\$ 30 \% 20$

1.7.2 This QAPP shall be submitted to the UMTRA Project Office for review and acceptance; the approved QAPP shall be issued as a controlled document.

1.7.3 This QAPP shall be reviewed once each calendar year. The review will be targeted for completion not sooner than 6 months and not later than 18 months following the last review. The results of this review shall be documented.

\subsubsection{QA requirements}

a. QA requirements contained in this QAPP shall apply to all TAC personnel, processes, and activities, including planning, scheduling, and costing.

b. The TAC QA program shall be implemented by all management, QA staff, and personnel at each level of the TAC organization. TAC personnel who conduct work activities are responsible for achieving at least the minimum specified level of quality. Performance objectives shall be established to ensure that quality is achieved. Initial estimates used in planning shall be based on sound data and assumptions relating to personnel, material/service, costs, availabilities, and productivity. 
c. TAC policy applies a graded approach to $\mathrm{QA}$, acknowledging that public health and safety are not always affected, and that an adequate level of quality is needed to ensure operational reliability and maintainability. Applicable portions of this document shall be implemented to the maximum degree for the quality-related functions that are identified as safety-related, and a less stringent but still viable quality level shall be used for other Project activities.

d. Organizational managers supervising the work shall ensure that the specified quality is achieved by using appropriate means of verification such as review, inspection, or observation.

e. Readiness reviews shall be performed prior to major scheduled planned work and should be performed to verify at least the following characteristics:

1. Work prerequisites have been satisfied.

2. Detailed technical and $Q A$ procedures have been reviewed for adequacy and appropriateness.

3. Personnel have been suitably trained and qualified.

4. The proper equipment, material, and resources are available.

f. The TAC OA staff's expertise may be used to assist the UMTRA Project Office staff in evaluating the adequacy of programmatic systems and technical products through verification techniques such as reviews, audits, surveillances, and operational readiness evaluations.

g. Direction and overview of TAC QA activities shall be provided by UMTRA Project Office QA personnel through audits, reviews, surveillances, and operational readiness evaluations (ORE).

\subsubsection{Environmental data operations}

a. All activities involving the generation, acquisition, and use of environmental data shall be planned and documented. The type and quality of these data shall be determined with respect to their intended uses. Establishing data collection objectives (DCO) will document the types of data required; establishing data quality objectives (DQO) will document the quality of data required. The ONARA $A C$ OWuality

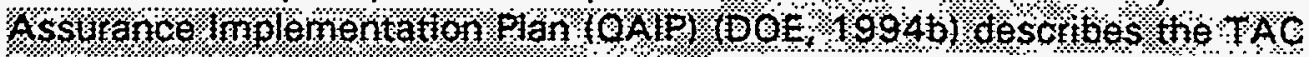
DCO and DeO process. 10 roore detall. Determining the type and quality of environmental data needed shall involve all data users as well as those personnel responsible for activities that affect data quality. 
b. The data collection process for characterizing environmental processes and conditions shall be defined, controlled, verified, and documented. The data collection design process includes the design of field sampling events, sample handling and custody, analytical operations, data validation methods, techniques for assessing limitations on data use, and data reporting and archiving requirements. The design process also applies to data compilation for modeling or additional studies.

c. The intended use of the data, including the potential for litigation, shall determine the extent of validation and documentation required during each sampling and analysis cycle. Any variables that determine or affect the quality of results shall be identified and controlled.

d. The data collection process shall ensure that data are traceable to the sampling and analytical procedures, performance standards, analysts, and measuring and test equipment (M\&TE). Data transfer, reduction, and validation requirements shall be determined and specified. Data interpretation and analysis needs shall also be determined and specified.

e. Procedures shall be established and implemented to ensure that only qualified and accepted services, equipment, or supplies are used in the environmental data operations and to maintain identification of the accepted equipment and supplies (i.e., chemicals, parts, and the like) in documents traceable to those items.

\subsubsection{Management information reporting and tracking}

a. Communication and information systems shall be established to ensure timely reporting, dissemination, and tracking of $Q A$ management information, such as the status of the implementation of QA programs, status of the resolutions of conditions adverse to quality, and status of $Q A$ overview results. Applicable reports shall be provided to management promptly. 


\subsection{PERSONNEL TRAINING AND QUALIFICATIONS}

\subsection{PURPOSE}

2.1.1 This section defines training requirements and guidance for TAC personnel, to ensure their familiarity with the requirements of the processes or activities they perform.

\subsection{GENERAL}

2.2.1 The TAC management shall ensure that plans and schedules are established for training activities needed to ensure that personnel demonstrate and maintain proficiency in performing their assigned work.

2.2.2 All personnel shall be capable of performing their assigned tasks and shall receive appropriate training before performing those tasks. Personnel shall have the education, experience, and training commensurate with the tasks and responsibilities associated with their work.

2.2.3 Required training shall be accomplished and documented to ensure that personnel understand the fundamentals of the processes or activities they perform and the requirements and regulations associated with those processes or activities. Mraining shall focus on the process or activity quality fequirements. the individual's esponstbitities for qualty and the importance of doing it ight the irst tine.

\section{$2.3 \quad$ TRAINING REQUIREMENTS}

2.3.1 Each year, supervisors shall review the job functions or tasks of personnel under their supervision and shall identify the extent of training that will be required for each member of their staff. These training requirements shall promote professional development, and progressive improvement and maintain proficiency; these requirements are not limited to attaining initial qualification.

2.3.2 Training requirements for management personnel shall include professional, managerial, communication, and interpersonal skills.

2.3.3 Persons verifying activities (such as lead auditors, auditors, or personnel conducting surveillances) shall be qualified in the principles, techniques, and requirements of the activity being performed. Specific qualification requirements for auditors and lead auditors are specified in Section 10.0 of this QAPP and in TAC SOPS.

2.3.4 Training may consist of on-the-job training, self-accomplished reading assignments, seminars, and presentations by qualified instructors. 
2.3.5 Specific details, instructions, and responsibilities regarding training requirements are provided in the TAC SOPS.

\section{$2.4 \quad$ PROFICIENCY EVALUATION}

2.4.1 Training is subject to ongoing review to determine program and instructional effectiveness. Training requirements shall be upgraded as additional improvements or requirements are identified.

2.4.2 Supervisors shall evaluate at least annually the proficiency of their personnel in the performance of their assigned duties. Appropriate training shall be provided to improve or maintain proficiency.

\subsection{DOCUMENTATION/RECORDS}

2.5.1 Documentation of qualification and training requirements shall be maintained by each individual's supervisor using the TRAIN.

2.5.2 Records of required training and certification shall be maintained by the supervisor, and a copy provided to the UMTRA Document Control Center at the end of each calendar year.

\subsection{VERIFICATION OF IMPLEMENTATION}

2.6.1 The TAC QA Department shall periodically assess training records during internal audits or reviews to ensure that the requirements in this section of the OAPP are being accomplished. 


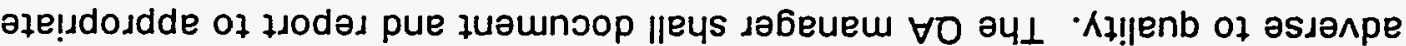

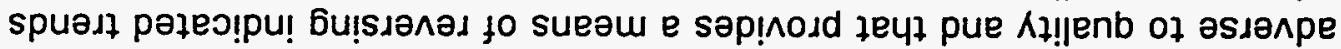

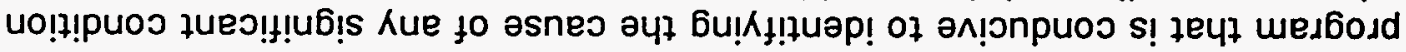
uo!łoe әл!

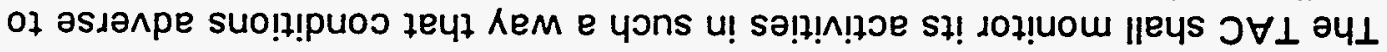

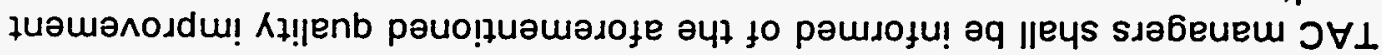

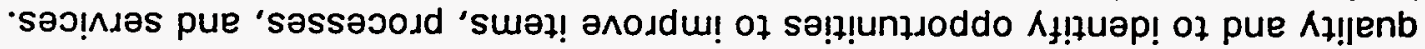

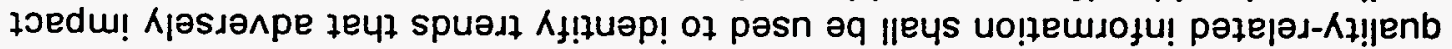

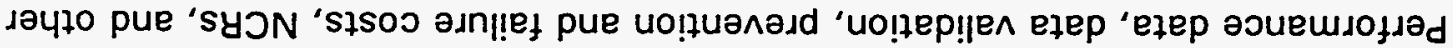

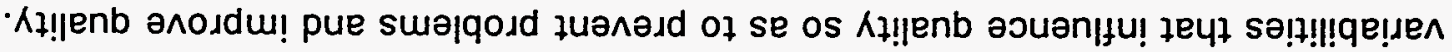

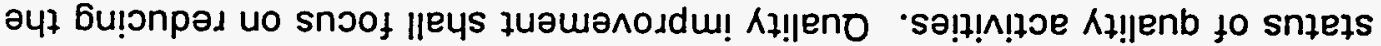

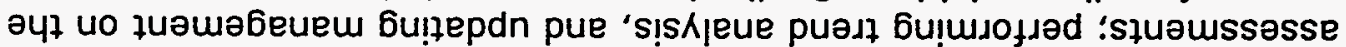

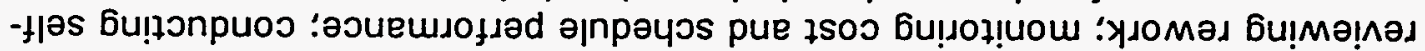

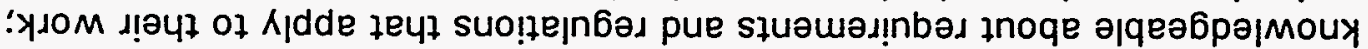

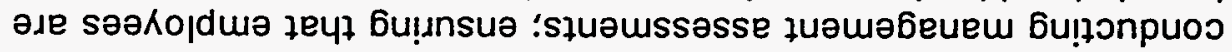

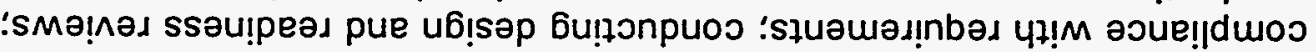

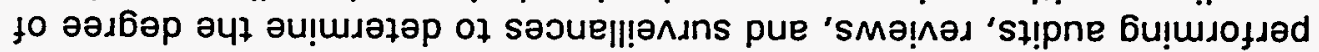

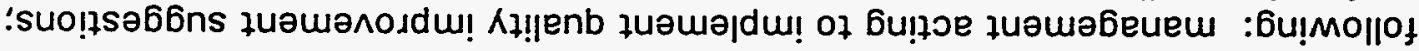

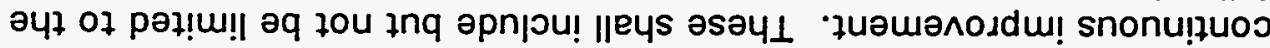

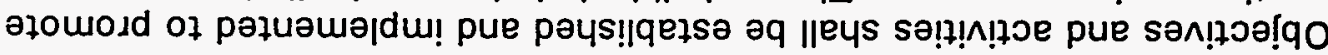

-suo!nsa66ns

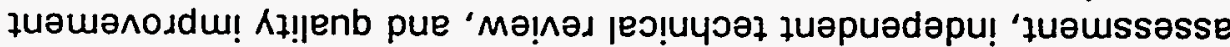

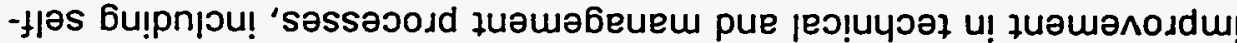

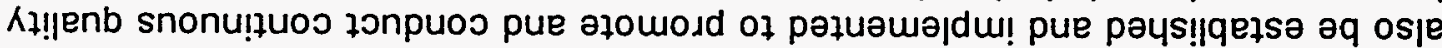

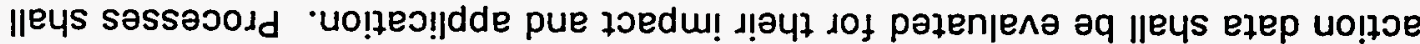

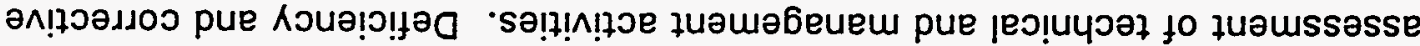

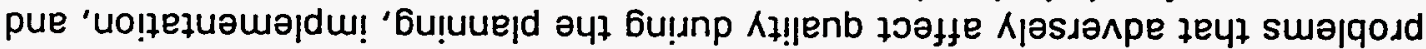

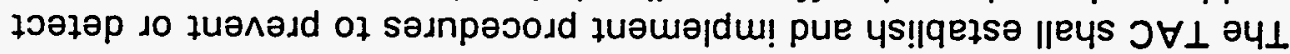

K)

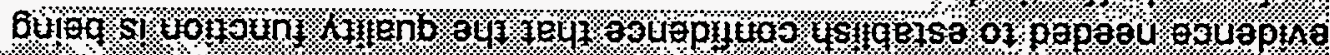

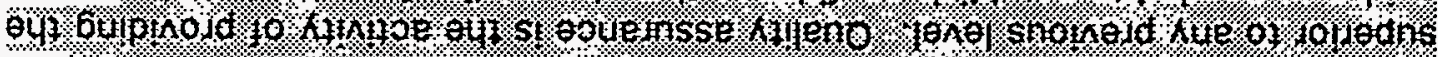

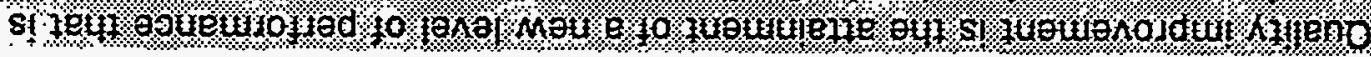

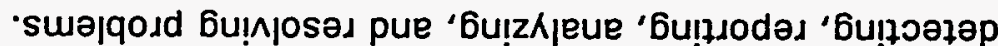

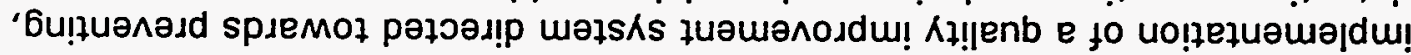

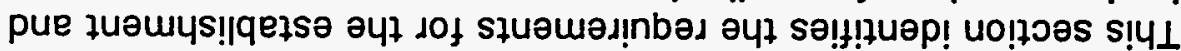


levels of management the identification of conditions adverse to quality, the cause of the conditions, and the corrective actions taken.

\subsection{NONCONFORMANCES}

3.3.1 A nonconformance is a variance from regulations, approved requirements, or SOPs that adversely affects safety, durability, performance, or any other basic objective that impacts quality.

3.3.2 The TAC shall provide appropriate procedures for nonconforming identification, documentation, segregation, recommended disposition, and notification of affected organizations. The TAC shall identify individuals who are delegated the responsibility and authority to approve the recommended disposition of a nonconforming material or item and shall evaluate nonconformances for quality trends.

3.3.3 It is the responsibility of all TAC employees to report any known nonconformances to TAC QA. The TAC QA Department, working in coordination with the responsible supervisor, shall follow up all nonconformances to ensure that nonconforming conditions are returned to original configuration, approved to use as is, reworked, or replaced.

3.3.4 After a nonconformance is identified, an NCR shall be originated by the group identifying the nonconformance. The NCR shall be completed, stating the regulation or requirement that was violated and the manner in which it was violated. Applicable supporting documentation shall be referenced or attached to the NCR.

3.3.5 Reporting a nonconformance shall not be considered in a negative manner, but rather shall be considered as an important tool that allows for and results in improved quality.

3.3.6 Nonconforming material shall be promptly identified, marked or tagged, and segregated, where practicable, to prevent inadvertent installation or use, further processing, or delivery. Nonconforming services and processes shall be curtailed until dispositioned. After satisfactory review of the NCR, the nonconformance shall be dispositioned by the TAC.

3.3.7 Nonconformances shall be documented in the NCR (Figure 3.1). Additionally, NCRs are numerically listed on the Deficiency/Nonconformance Report Log. The log serves as a monitoring and follow-up device (Figure 3.2). Because of the significance or urgency associated with a nonconforming condition, notification may be made by telephone or in person; however, an NCR shall be completed as soon as possible after the informal notification.

3.3.8 The NCR shall be provided to the QA manager and the qualified organization responsible for disposition. 
JACOBS ENGINEERING GROUP INC.

ALBUQUERQUE OPERATIONS

QUALITY ASSURANCE NON CONFORMANCE REPORT

\begin{tabular}{|l|l|}
\hline ITEM & NCR NO. \\
\hline LOCATION & DATE \\
\hline
\end{tabular}

\begin{tabular}{lll}
\hline TASK NO. & ITEM NO. & REF. DWG. CODE OR SPEC \\
\hline
\end{tabular}

NONCONFORMANCE /DEVIATIONS

\begin{tabular}{|l|l|}
\hline INSPECTOR & DATE \\
\hline
\end{tabular}

Disposition $\square$ Replace $\square$ Rework $\square$ Repair $\square$ USe as is $\square$ qa impacts

\begin{tabular}{|l|l|l|}
\hline INSPECTOR & RESIDENT SITE MANAGER & DOE SITE REP. DATE \\
\hline FINAL STATUS $\quad \square$ REJECT & REMARKS
\end{tabular}

QUALITY CONTROL INSPECTION ACCEPTANCE

DATE

FIGURE 3.1

NONCONFORMANCE REPORT 


\begin{tabular}{|c|c|c|c|c|c|c|}
\hline \multirow{3}{*}{$\begin{array}{l}\text { LINE } \\
\text { NO. }\end{array}$} & \multicolumn{4}{|c|}{$\begin{array}{l}\text { JE. JACOBS ENGINEERING GROUP INC. } \\
\text { QUALLITY ASSURANCE DEFICIENCYINONCONORMANACE REPORT LOG }\end{array}$} & \multirow{3}{*}{$\mid \begin{array}{c}\text { DATE } \\
\text { ENTERED }\end{array}$} & \multirow{3}{*}{$\begin{array}{c}\text { DATE } \\
\text { CLEAREL }\end{array}$} \\
\hline & \multirow{2}{*}{\begin{tabular}{|c}
$\begin{array}{c}\text { DEFICIENCY } \\
\text { NO. }\end{array}$ \\
SITE
\end{tabular}} & \multirow{2}{*}{$\begin{array}{c}\text { NCR NO. } \\
\text { SITE }\end{array}$} & \multirow{2}{*}{$\begin{array}{l}\text { REFERENCE } \\
\text { DALY } \\
\text { INSPECTION } \\
\text { REPORT NO. }\end{array}$} & \multirow{2}{*}{$\begin{array}{l}\text { DEFICIENCY/NONCONFORMANCE REPORT } \\
\text { DESCRIPTION }\end{array}$} & & \\
\hline & & & & & & \\
\hline & & & & & & \\
\hline & & & & & & \\
\hline & & & & & & \\
\hline & & & & & & \\
\hline & & & & & & \\
\hline & & & & & & \\
\hline & & & & & & \\
\hline & & & & & & \\
\hline & & & & & & \\
\hline & & & & & & \\
\hline & & & & & & \\
\hline & & & & & & \\
\hline & & & & & & \\
\hline & & & & & & \\
\hline & & & & & & \\
\hline & & & & & & \\
\hline & & & & & & \\
\hline & & & & & & \\
\hline & & & & & & \\
\hline & & & DEFICIENC & $\begin{array}{l}\text { GURE } 3.2 \\
\text { NFORMANCE REPORT LOG }\end{array}$ & & \\
\hline
\end{tabular}


3.3.9 Modifications, repairs, rework, use-as-is, and replacements shall be inspected or tested to verify acceptability in accordance with the original requirements and specifications. The justification for disposition shall be documented.

\subsection{CORRECTIVE ACTION}

3.4.1 All conditions adverse to quality shall be promptly identified, documented, and corrected as soon as practicable.

3.4.2 The UMTRA Project Office shall approve corrective actions on nonconforming items, processes, and services that may affect the licensing of a site.

3.4.3 If corrective action is deemed necessary, a corrective action request (CAR) (Figure 3.3) shall be prepared by QA personnel. The CAR will then be reviewed and approved by the TAC OA manager, to ensure completeness and accuracy.

3.4.4 When the top portion of the CAR is complete, the CAR shall be entered numerically on a corrective action request log (Figure 3.4), to maintain control and accountability. The CAR shall then be issued to the responsible individual or group from which the corrective action response is requested. Copies of the CAR shall be distributed to appropriate Project personnel by the TAC organization responsible for the item, process, or service that was nonconforming.

3.4.5 An evaluation of any adverse condition shall be conducted and shall include trend analysis and identification of the root cause, extent, and effects on the UMTRA Program.

3.4.6 Upon completion of the evaluation, the applicable corrective action shall be identified. This corrective action shall address the root cause, identify the actions necessary to preclude recurrence, identify lessons learned, and define a schedule for the actions. The corrective action shall be reviewed by the appropriate manager to ensure that proper focus is given, adequate resources are allocated, and difficult issues are resolved.

3.4.7 This recommended corrective action shall be documented in the CAR, which shall be returned to the $\mathrm{QA}$ manager for acceptance or rejection. If the recommended corrective action is accepted, the QA manager shall sign the CAR, indicating closeout, and shall update the CAR log accordingly.

3.4.8 If the corrective action response is unsatisfactory, the QA manager shall return the CAR to the affected individual or organization to obtain satisfactory resolution.

3.4.9 The QA Department shall conduct a follow-up investigation to verify implementation of the corrective actions. Additional reviews may be performed to verify that corrective action is effective in preventing a recurrence of the adverse condition. 
JACOBS ENGINEERING GROUP INC.

ALBUQUERQUE OPERATIONS

QUALITY ASSURANCE DEPARTMENT CORRECTIVE ACTION REQUEST

PROJECT: JOB: SITE: PAGE OF REQUEST NO. GROUP/ORGANIZATION REPLY DUE DATE

REFERENCE DOCUMENT:

CONDITION DESCRIPTION:

REPLY REQUESTED FROM ACTION ADDRESSEE INITIATED BY

CAUSE AND CORRECTIVE ACTION

PREPARED BY NAME

CORRECTIVE ACTION VERIFIED BY DISTRIBUTION:
AUTHORIZED BY

PROJECT QA MANAGER DATE

FIGURE 3.3

CORRECTIVE ACTION REQUEST 


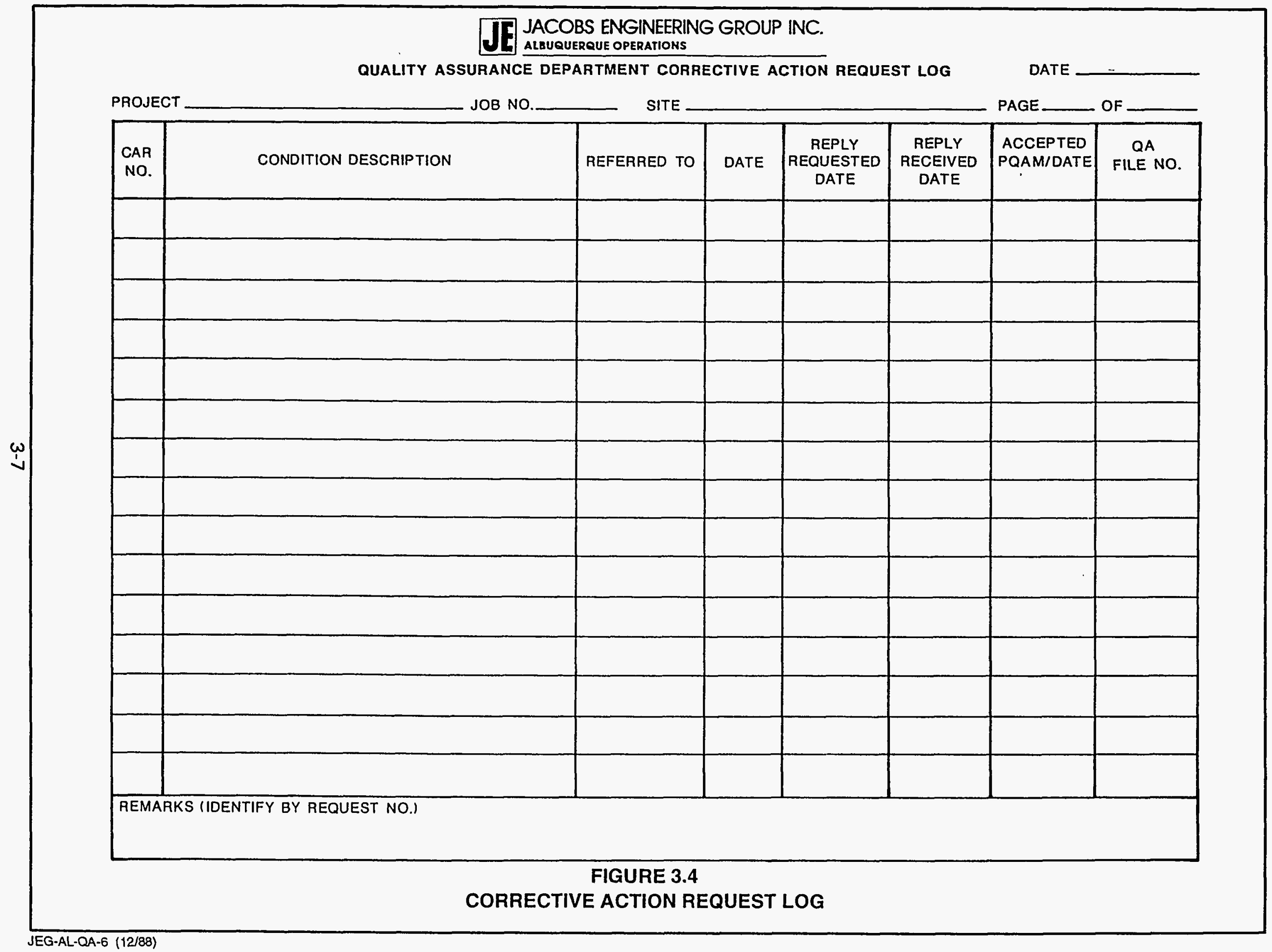




\subsection{ADVERSE CONDITIONS IDENTIFIED BY THE UMTRA PROJECT OFFICE}

3.5.1 All adverse conditions identified by the UMTRA Project Office that are applicable to the TAC shall be immediately brought to the attention of the TAC Project Manager. The TAC Project Manager shall take immediate corrective action and report corrective action progress within the time period designated by the UMTRA Project Office.

\subsection{DOCUMENTATION}

3.6.1 Reporting nonconformances, disposition activities, evaluations of adverse quality activities, corrective actions, and verification of corrective actions shall be documented.

\subsection{VERIFICATION}

3.7.1 The TAC QA Department shall verify the implementation and effectiveness of quality improvements using audits, in-process surveillances, and reviews. 


\subsection{DOCUMENTS AND RECORDS}

\subsection{DOCUMENTS}

\subsubsection{Purpose}

a. This section establishes a system to ensure that documents that establish policies, prescribe work, or specify requirements are properly reviewed, approved, and released by authorized persons and are distributed to and used at the location where the prescribed activity is performed.

\subsubsection{General}

a. The preparation, issue, and revision of documents that specify quality requirements or prescribe activities affecting quality shall be controlled to ensure that correct documents are used. Such documents, including changes thereto, shall be reviewed for adequacy and approved for release by authorized personnel.

\subsubsection{Document preparation, revision, review, and approval}

a. Procedures for the preparation and revision of plans, manuals, procedures, instructions, reports, and other documents shall address at least the following requirements:

1. Identification of the individuals or organizations responsible for the preparation, revision, review, approval, release, and control of the documents.

2. Review of documents for adequacy, completeness, and correctness by individuals or organizational elements responsible for implementation. Document review shall be completed by individuals other than the preparers.

3. Access by reviewing organizations to pertinent background data or information to ensure adequacy, completeness, and correctness prior to approval and issuance.

4. Resolution of review comments that are considered mandatory by the reviewing organization. Resolution shall be accomplished in accordance with TAC SOPs before a document is approved and issued. Review comments and resolutions shall be documented and maintained. 


\subsubsection{Issuance and distribution}

a. Document issuance and distribution shall be controlled to ensure that correct, applicable, and current documents are available to the personnel at the work location before work begins. Document control procedures provide for the following:

1. Identifying and marking documents, including documents released before the approval process is complete.

2. Maintaining document distribution lists.

3. Marking or removing obsolete or superseded documents.

4. Maintaining an index that includes document revision status.

\subsubsection{Controlled documents}

a. Controlled documents meet all requirements associated with document preparation, approval, and issuance, and are considered important enough that only the latest issues of the documents should be used.

b. Provisions for controlled documents include:

1. Identifying documents to be controlled and their specified distribution, including documents released before the approval process is completed.

2. Acknowledging receipt of document transmittal forms.

3. Maintaining controlled document distribution lists.

4. Controlling superseded and canceled documents. This should include measures to ensure that only correct documents are in use. Record copies should be marked "Superseded" or "Canceled" and kept for a specified retention period.

5. Maintaining an index giving revision status for controlled documents.

\subsubsection{Document changes}

a. All changes to documents shall be accomplished in accordance with the same review and approval requirements as were used for the original document. Approved changes shall be distributed in accordance with the latest approved distribution list. 


\subsubsection{Implementing requirements}

a. Detailed procedures for the preparation, review, and approval of TAC SOPS and the preparation, review, and approval of TAC-generated documents are provided in the TAC SOPS.

\subsection{RECORDS}

\subsubsection{Purpose}

a. This section provides the methods for the receipt, index, identification, handling, filing, validation, storage, retrievability, and disposition of records.

\subsubsection{General}

a. The TAC shall maintain sufficient records to support conclusions reached from investigations, tests, or other remedial action activities accomplished under the auspices of the UMTRA Project. The TAC shall provide the support needed to receive, organize, maintain, and store all records generated during the course of the UMTRA Project. While the record keeping tasks shall be assigned to the TAC, the UMTRA Project Office shall be responsible for all record keeping requirements.

b. The TAC shall ensure that specific required records are prepared, retained, and maintained as work is performed to document the quality of items and activities affecting quality.

c. The TAC shall ensure that the records are legible, identifiable, retrievable, and protected against damage, deterioration, or loss. Requirements and responsibilities for record transmittal, distribution, retention, maintenance, and disposition are addressed in Section 12.0 of the UMTRA Project Document Control System Manual (PDCS) (DOE, 1994c).

\subsubsection{Records requirements}

a. The TAC records program activities shall be defined, implemented, and enforced in accordance with written procedures and the PDCS manual $\left(D O E, 199^{4} \mathrm{c}\right)$. These procedures describe the methods used to create, identify, control, process, organize, and distribute records.

b. The records program shall ensure that sufficient records (for example, records of design, environmental conditions, applied research and development, procurement, construction, data acquisition, assessments, inspection, testing, maintenance, and modification) are specified, prepared, reviewed, approved, and maintained to accurately reflect completed work. The maintenance of records shall include provisions for 
retention, protection, preservation, traceability, accountability, retrievability, and disposition of UMTRA Project records.

\subsubsection{Procedure}

\section{a. Records processing}

1. All records shall be submitted on forms which legibly and completely record the required data. Records shall be considered valid only when they are stamped, signed, or otherwise authenticated and dated by authorized personnel.

b. Record types

1. Documents that are considered records shall consist, at a minimum, of the following:

a. Personnel records (training, qualifications, and certifications).

b. Design review files.

c. Procurement document review.

d. Internal/external audit files and schedules.

e. In-process surveillances.

f. Nonconformance reports/corrective action requests.

g. Source evaluation reports.

h. Client $Q A$ directives.

i. QA program plan.

j. SOPs.

k. Engineering specifications.

I. Maps.

m. Lab sample analyses.

n. Drawings.

o. Project correspondence.

p. Photographs.

q. Microfilm.

r. Certification documents.

s. Field data.

\subsubsection{Records filing}

a. Records shall be filed so as to provide timely retrievability. Methods shall be established to identify the records, record retention times, and record storage locations.

b. A record index has been developed and implemented to include a record index numbering system, storage location, and retention time. Index requirements are defined in the PDCS manual (DOE, 199/4c̈). 
c. For records that require special processing and control, such as computer codes or information on high density-media or optical disks, hardware and software required to maintain and access records shall be controlled to ensure that records are usable.

\subsubsection{Record storage}

a. The UMTRA central files are located at the TAC Albuquerque Operations Office. The PDCS facilities shall provide precautions against destruction of records from fire or natural causes. The TAC shall implement the necessary fire and security protection as specified in the PDCS manual (DOE, 199/4), and shall provide controlled access to records storage areas.

\subsubsection{Corrected information in records}

a. Records may be corrected in accordance with procedures which provide for appropriate review or approval by the originating organization. The correction shall include the date and the identification of the person authorized to issue such correction.

\subsubsection{Disposition}

a. The TAC shall retain records in accordance with Section 4.2 of this QAPP and with applicable DOE project requirements until these records are requested by the $D O E$.

\subsubsection{UMTRA Project document control system}

a. The TAC shall be responsible for ensuring the efficient operation of the UMTRA PDCS. The TAC shall provide support and guidance to the UMTRA Project Office in the operation of the UMTRA PDCS by recommending changes, improvements, policies, and procedures. The TAC shall be responsible for reviewing and updating the PDCS manual (DOE, $1994 \%$ ) annually, or as significant changes warrant.

\subsubsection{Records system}

a. Temporary records holding facilities are reserved for storage of inactive records and may not meet the physical requirements or have appropriate staff to maintain active records. Active records requiring special handling, storage, and processing should not be sent to records holding facilities. Users should refer to the General Records Schedule (GRS) or DOE Order 1324.2A for retention and disposition of records.

b. The National Archives and Records Administration (NARA) exercises final authority for approving the disposition of Federal records. Use of the 
GRS, which is published by the NARA, and the DOE unique schedules approved by the NARA are mandatory.

c. Some standards which provide interpretive OA guidance may differ in records management terminology from the NARA requirements. In those instances, care should be taken to ensure that the requirements of both the NARA and the standards are followed.

\subsection{VERIFICATION OF IMPLEMENTATION}

4.3.1 The TAC QA Department shall annually audit the status of document control and the PDCS to ensure that documents and records are controlled in accordance with this QAPP and applicable Project requirements. 


\subsection{WORK PROCESSES}

\section{$5.1 \quad$ WORK}

\subsubsection{Purpose}

a. This section defines requirements that ensure that activities affecting quality shall be prescribed by and performed in accordance with documented instructions, procedures, or drawings of an appropriate type.

\subsubsection{Requirements}

a. Activities on the UMTRA Project are prescribed by and controlled in accordance with DOE Orders. The DOE Orders are established by DOE Headquarters (HO); transmitted to DOE-AL, UMTRA Project Office; and implemented by the TAC. Work controls, which include instructions, procedures, and drawings, shall be applied to processes and activities performed by the TAC.

\subsubsection{Work processes, instructions, procedures, and drawings}

a. All activities affecting quality on the UMTRA Project shall be defined by SOPs and drawings that are prepared, reviewed, and approved in accordance with this section of the QAPP.

b. These documents shall include appropriate quantitative or qualitative acceptance criteria for determining that prescribed activities have been satisfactorily accomplished. They also shall specify the records or documentation required to record the compliance with requirements. While administrative procedures may require specific activities, acceptance criteria are not normally included in these documents.

c. All work should be planned, authorized, and accomplished under controlled conditions following technical standards, SOPs, drawings, or other appropriate means of a detail commensurate with the complexity and risk of the work.

Copies of these documents shall be maintained in the work area and shall be available for reference by personnel performing the work.

\subsubsection{Quality responsibilities}

a. All TAC personnel are responsible for the quality of their work. Performance objectives shall be established to ensure that quality work is achieved. Supervisors shall ensure that personnel under their supervision are provided the necessary training, resources, and administrative controls to accomplish their assigned tasks. Criteria describing acceptable work 
performance shall be defined. Supervisors shall review work and related information to ensure that the desired quality is achieved and to identify areas that need improvement.

b. All personnel shall receive appropriate training prior to performing their work activities. Personnel shall be knowledgeable about the requirements for the work they perform and the capability of the tools and processes they use.

\subsection{IDENTIFICATION AND CONTROL OF ITEMS}

\subsubsection{Purpose}

a. This section specifies the requirements to identify and control materials, parts, and components, including partially fabricated assemblies, to prevent the use of incorrect or defective items during Project activities.

\subsubsection{General}

a. The TAC shall ensure that only specified, correct, and accepted items are used and installed during Project activities.

b. The TAC shall ensure that materials, parts, and components are properly related to applicable control documents, such as drawings, specifications, similar technical documents or procurement documents pertinent to the prescribed activities.

c. The TAC shall ensure that applicable codes, standards, or specification requirements for traceability are implemented for specific inspection or test records and for material traceability to lot numbers.

\subsubsection{Requirements}

a. Processes shall be established and implemented to identify, control, and maintain items purchased for use on the UMTRA Project. Materials, parts, and components used by the TAC shall be identified and controlled.

b. Identification of the materials, parts, and components shall be maintained to ensure appropriate traceability. Physical identification shall be used to the maximum extent possible. Where physical identification on the items is either impractical or insufficient, physical separation, procedural control, or other appropriate means shall be employed. Procedures shall be established and implemented to control consumables and items with limited shelf or operating life, prevent the use of incorrect or defective items, and control samples (including chain of custody). Identification markings shall provide a clear and legible identification but not detrimentally affect the function or life of the items. 


\subsubsection{Procedures}

a. Receiving inspection

1. The TAC organization that receives materials and services shall be responsible for verifying that procured items are identified by purchase order. Items that cannot be properly identified shall be placed in a hold status until disposition can be adequately determined. Items that are found acceptable shall be identified as such. After satisfactory receiving inspection is documented, acceptable material shall be available for use.

\section{b. Storage}

1. Storage areas will be monitored periodically by TAC organizations to ensure that proper identification of materials is maintained. If items are released to the field for erection or installation, proper identification shall be maintained. Further storage instructions are described in Section $\mathbf{5 . 3}$ of this QAPP.

\section{c. In-process control}

1. Through the use of drawings, specifications, work orders, and similar technical documents, TAC organizations shall verify that proper identification of items is maintained throughout fabrication, erection, and installation activities. Responsibility for identification control shall include the maintenance, retention, or submission of required documents (such as instruction manuals, parts lists, and the like).

d. Suppliers and subcontractors

1. Suppliers and subcontractors shall establish methods for identification and control of items, including partially fabricated subassemblies, so that all segments of the fabrication and manufacturing process can be verified, traced, and checked for compliance with procurement documents and/or subcontracts.

2. Source surveillance shall be performed, as required, by the TAC QA Department. The TAC QA Department shall ensure that identification markings correspond at all stages, from initial receipt of order through fabrication to shipment. The TAC OA Department shall also verify that corresponding documentation meets specified requirements. 


\subsection{HANDLING, STORAGE, AND SHIPPING}

\subsubsection{Purpose}

a. This section provides for quality controls $(\mathrm{OC})$ in the handling, storage, and shipping of items.

\subsubsection{General}

a. Handling, storage, and shipping of items shall be conducted in accordance with established work and inspection instructions, drawings, specifications, shipment instructions, or other pertinent documents or procedures specified for each activity. The TAC shall ensure the following:

1. Handling, storing, cleaning, packaging, shipping, and preserving of items shall be controlled to prevent damage or loss, minimize deterioration, and protect personnel.

2. Proper identification markings, controls, and traceability of materials are maintained.

3. Materials shall be stored in accordance with project requirements.

4. Withdrawal of items from storage shall be appropriately documented.

\subsubsection{Requirements}

a. Handling, storing, cleaning, packaging, shipping, and preserving field and laboratory environmental samples shall meet chain-of-custody requirements and shall be performed in accordance with the TAC SOPs.

b. Marking and labeling shall be maintained and legible throughout packaging, shipping, handling, and storing activities. The information provided by marking and labeling shall identify items and provide instructions or special controls to preserve the items' integrity. Off-site transportation requirements shall be established and implemented through written procedures.

\subsubsection{Procedure}

a. Handling

1. Items transferred to or removed from storage shall be handled so as to preclude damage. 
2. Traceability shall be maintained. When specified, critical, heavy, and major items shall be handled in accordance with the manufacturer's instructions.

3. After receiving inspection is complete, items shall be stored in appropriate areas, with applicable identification clearly visible.

b. Storage

1. Storage facilities shall have controlled access to the extent necessary to prevent unauthorized personnel from obtaining items.

2. Maintenance, care, and protection of items shall be performed so as to preclude damage or deterioration.

3. The withdrawal of items from storage shall be documented and referenced to applicable drawings or specifications by authorized personnel, to ensure that correct items are released.

c. Shipping

1. Written procedures, engineering specifications, and a purchase orders shall provide adequate instructions for marking and labeling items and their shipping containers. Markings shall be adequate to identify, maintain, and preserve the shipment.

d. Special items

1. When items are extremely critical, sensitive, perishable, or valuable, TAC Engineering shall write specific procedures for handling, storing, packaging, shipping, and preserving these items. These procedures shall include applicable requirements for special coverings and protective environments, specific moisture content and temperature levels. These special items shall be specified in the procurement documents and receiving inspection shall be performed accordingly.

\subsection{CALIBRATION AND MAINTENANCE OF MONITORING AND DATA COLLECTION EQUIPMENT}

\subsubsection{Purpose}

a. The purpose of this section is to establish a calibration and maintenance system to ensure that all monitoring and data collection equipment is of the proper type, range, and accuracy; is uniquely identified; and is traceable to its calibration test data. 


\subsubsection{General}

a. A system has been established and implemented through written procedures to control the calibration, maintenance, and use of M\&TE for monitoring and data collection.

\subsubsection{Requirements}

a. Monitoring and data collection equipment shall be of the accuracy and type suitable for the intended use. Equipment calibration certification shall be traceable to national standards. Equipment requiring calibration shall be identified by a serial number or a control identification number. The equipment shall have a calibration tag or sticker affixed in a conspicuous location to readily identify its calibration status. Typical information found on the calibration tag or sticker would be the calibration date, instrument serial number, next calibration date, and the name of the person who calibrated the instrument.

b. Monitoring and data collection equipment that is of a special design for a particular activity shall be designed, developed, and manufactured or procured under the control of the TAC organization involved. Before any equipment is used, a complete functional check shall be conducted in accordance with written procedures to ensure conformance to specifications and to ensure that the equipment is properly calibrated.

c. Written procedures for calibrating specific monitoring and data collection equipment shall be provided to the operators to ensure that calibration requirements are identified and followed. Monitoring and data collection equipment shall be calibrated at specified intervals on the basis of each item's required accuracy, intended use, frequency of use, stability characteristics, and other conditions affecting its performance.

d. The equipment shall be calibrated against standards that will ensure calibration within required tolerances. Monitoring and data collection equipment shall be labeled, tagged, or otherwise controlled to indicate its calibration status and ensure traceability to calibration test data. Records of monitoring and data collection equipment shall include scheduled calibrations, if applicable. Calibration records of equipment requiring calibration shall be maintained. References or standards used to perform calibrations shall have calibration certificates traceable to National Institute of Standards and Technology (NIST) standards or documentation from other nationally recognized standards.

e. Monitoring and data collection equipment found out of calibration or out of tolerance shall be tagged and/or segregated and not used until it is successfully recalibrated. 
f. Maintenance shall be accomplished at specified intervals and in accordance with approved procedures.

\subsection{VERIFICATION}

5.5.1 The TAC QA Department will verify the implementation and effectiveness of work; identification and control of items; handling, storage, and shipping; and calibration and maintenance of monitoring and data collection equipment using audits, in-process surveillances, and reviews. 


\subsection{DESIGN}

\subsection{PURPOSE}

6.1.1 The purpose of this section is to establish a process for the control of design activities performed by the TAC design organization.

\subsection{GENERAL}

6.2.1 The designs used on the UMTRA Project shall be defined, controlled, and verified in accordance with written procedures. Applicable design input shall be appropriately specified on a timely basis and correctly translated into design documents. Design interface shall be identified and controlled through written procedures.

6.2.2 The TAC shall ensure that design intent and requirements and appropriate quality standards are incorporated into specifications, drawings, procedures, and instructions in accordance with applicable Project requirements.

6.2.3 The TAC shall ensure that sources of design information are traceable, adequate controls are maintained, and designs are properly verified in accordance with written procedures.

6.2.4 The TAC shall ensure that changes in, or deviations from, design requirements and quality standards are systematically identified, documented, and controlled.

\subsection{REQUIREMENTS}

6.3.1 Procedures shall specify the following:

a. Describe the process by which design activities from conceptual design through final design are planned, controlled, and implemented.

b. Describe the control of design inputs, organizational interfaces, processes, outputs, records review, changes, and deficiencies.

c. Address the control of scientific investigation.

\subsection{UMTRA PROJECT OFFICE CONTROL OF DESIGN ACTIVITIES}

6.4.1 TAC design activities shall be accomplished using sound engineering/scientific principles and appropriate standards, in accordance with procedures described in SOPs. The TAC is responsible for the development of the conceptual design for each remedial action site. Conceptual designs are approved by the UMTRA Project Manager, and submitted to the Remedial Action Contractor (RAC) for final design. The final design for each remedial action site is subject to a TAC review and subsequent approval by the UMTRA Project Manager. 


\subsection{SCIENTIFIC INVESTIGATION}

6.5.1 The adequacy of a disposal cell depends heavily upon the results of the scientific investigations conducted to characterize the disposal site. Therefore, the performance of these scientific investigations shall be controlled in accordance with TAC SOPS.

6.5.2 The TAC shall conduct scientific investigations at the direction of the UMTRA Project Office. The TAC shall perform special technical studies to investigate general areas of programmatic impact that 1) result in establishment of criteria or Project direction, or 2) confirm results or conclusions of participating organizations. Scopes of work prepared by the TAC for subcontract applications shall define these special study activities. Controls for the review, approval, and changes to these scopes of work shall be conducted in accordance with TAC SOPS.

\subsection{PROCESSING DATA}

6.6.1 Data collection and processing shall be conducted by the TAC at the direction of the UMTRA Project Office. The UMTRA Project Office shall be responsible for the preparation and control of requirement documents for the system elements. Data collection, qualification, analysis, identification, and recording activities related to the design of the disposal sites shall be controlled in accordance with TAC SOPS.

\subsection{DESIGN PROCESS}

6.7.1 Applicable design input, such as design bases, performance and reliability requirements, codes, and standards, shall be identified, documented, and correctly translated into design output, such as specifications, drawings, procedures, and instructions. Their selection shall be reviewed and approved by all technical fields that are affected by or with construction activities. The review process shall also include a $Q A$ review.

6.7.2 The design input for the requirement documents shall be controlled by the UMTRA Project Office. The design input shall be specified and approved on a timely basis, and to the level of detail necessary to provide a consistent basis for making design decisions, accomplishing design verifications, and evaluating design changes.

6.7.3 Changes from approved design input, including the reason for the changes, shall be identified, approved, documented, and controlled.

6.7.4 Design interface shall be identified and controlled, and design efforts shall be coordinated among and within TAC organizations. Interface controls shall include the assignment of responsibility and establishment of procedures among participating design organizations. 
6.7.5 The responsible TAC group shall prescribe the control of design interface by 1) identifying who is responsible for each element of the design, 2) establishing interface controls among participating design organizations, 3) describing the process for developing an integrated design, and 4) establishing requirements for documenting, maintaining, and controlling a technical baseline. Calculations developed as part of the design process shall be reviewed and approved.

6.7.6 Appropriate quality standards shall be identified and documented, and their selection reviewed and approved. Changes from specified quality standards, including the reason for the changes, shall be identified, approved, documented, and controlled. The final design (approved design output documents and approved changes thereto) shall be related to the design input by documentation in sufficient detail to permit verification.

\subsection{DESIGN ANALYSIS}

6.8.1 Design analysis shall be planned, controlled, and documented.

6.8.2 Design analysis documents shall be legible and suitable for reproduction, filing, and retrieval. They shall be sufficiently detailed (as to purpose, method, assumptions, design input, references, and units), that a person technically qualified in the subject can review and understand the analysis and verify the adequacy of the results without consulting the originator.

6.8.3 Calculations shall be identifiable by subject (including structure, system, or component to which the calculation applies), originator, reviewer, and date. Calculations shall be retrievable.

\subsection{DESIGN VERIFICATION}

6.9.1 Design control measures, such as design reviews, alternate calculations, or performance qualification tests, shall be applied to verify the adequacy of design.

6.9.2 The adequacy of technical documents shall be verified prior to approval and issuance for use in accordance with written procedures described in the TAC's SOPS. The acceptability of design work and documents, including design input, processes, output, and changes, shall be verified. Design verification shall be . performed by qualified individuals or groups other than those who performed the original design, although they may be from the same organization. The extent of verification should be based on the complexity, risk, and uniqueness of the design. Verification methods include, but are not limited to, design reviews, alternate calculations, and qualification testing. Separate verification may not be needed for multiple uses of identical or previously proven designs, unless they are intended for different applications or different performance criteria.

6.9.3 The RAC shall host the design verification. The TAC site manager and TAC site engineer shall attend. 
6.9.4 Testing to verify or validate acceptability of a specific design feature should demonstrate acceptable performance under conditions that simulate the most adverse design conditions.

6.9.5 The TAC manager of the responsible design group shall identify and document the particular design verification method(s) used.

6.9.6 Design verification shall be completed before design output is used by other organizations or to support other work, such as procurement, manufacture, construction, or experiment. When this timing cannot be achieved, the unverified portion of the design should be identified and controlled. In all cases, design verification shall be complete before an item is functional and before installation becomes irreversible (requiring extensive demolition or rework).

6.9.7 For the remedial action disposal sites, a design review may be needed to verify a design.

\subsection{DESIGN REVIEWS}

6.10.1 Design reviews will be conducted when the adequacy of information or the suitability of procedures and methods cannot be established through tests, alternate calculations, or reference to established standards. Design reviews will be conducted at appropriate times and as necessary by all applicable design groups involved in the UMTRA Project. These reviews will verify the design and documentation, and ensure that quality requirements are specified.

6.10.2 Design reviews shall be performed in accordance with written procedures by cognizant personnel to ensure that the final design is correct and satisfactory.

\subsection{COMPUTER SOFTWARE}

6.11.1 Computer programs used by the TAC shall be proven through previous use, or validated through testing or simulation before to use. The TAC's computer programs shall be controlled in accordance with written procedures.

\subsection{READINESS/ON-BOARD REVIEWS FOR DESIGN ACTIVITIES}

6.12.1 Readiness/on-board reviews shall be conducted prior to the start of a design activity or various design phases for each site, such as collection of site characterization data or model development. The RAC shall host the readiness/on-board review. The TAC site manager and site engineer shall represent the TAC. Readiness/on-board reviews shall ensure conformance to the following minimum elements:

a. The required engineering approach to design development is factored into design schedules and related planning documents. 
b. Applicable regulatory requirements, codes, standards, and quality levels are identified. SOPs reflect these required design inputs.

c. Design responsibilities and interface are defined in written procedures.

d. Procedures discuss requirements for in-process and design reviews. Design schedules identify milestone design reviews.

e. Procedures exist for baselining design documents and controlling subsequent changes.

6.12.2 The results of the readiness/on-board reviews shall be documented and approved by the DOE site engineer and shall become part of the site records.

\subsection{DESIGN CHANGE CONTROL}

6.13.1 Changes to design documents shall be justified and processed using the same methods that were applied to the preparation of the original document. Changes shall be controlled, reviewed, and approved by the organizations that reviewed and approved the original design documents. Changes shall incorporate all applicable regulations and standards. The impact of design changes on procedures and training shall be evaluated. The changes shall be communicated to all affected groups or individuals. The RAC shall be responsible for design change control.

\subsection{DESIGN ERROR AND DESIGN DEFICIENCY CONTROL}

6.14.1 Errors and deficiencies identified in approved design documents and design information used by the UMTRA Project Office will be controlled and resolved in accordance with Section 3.0 of this QAPP. The impact of such deficiencies on previous work will be evaluated and necessary corrective measures will be applied.

6.14.2 Design deficiency reports shall be sent to TAC management for information or action. Design deficiencies shall be tracked by the responsible organization until disposition has been assigned, approved, and implemented. Deficiencies that represent conditions adverse to quality will be documented and controlled in accordance with Section 3.0 of this QAPP.

\subsection{RECORDS}

6.15.1 Design records shall be maintained to document that the design and verification process complied with this QAPP. Design records shall include not only the final design output and its revision, but also important design steps (calculations, analyses, and computer programs) and input sources that support final output. 


\subsection{VERIFICATION}

6.16.1 The TAC OA Department shall verify implementation of these design requirements through audits, in-process surveillances, and reviews. 


\subsection{PROCUREMENT PURPOSE}

\subsection{PURPOSE}

7.1.1 This section specifies controls to ensure that purchased materials, equipment, and services conform to procurement documents, subcontracts, design specifications, and applicable codes and standards.

\subsection{GENERAL}

7.2.1 The procurement of items and services shall be controlled to ensure conformance with specified requirements. Such control shall provide for the following, as appropriate:

a. Incorporation of applicable requirements in procurement documents.

b. Source evaluation and selection.

c. Evaluation of objective evidence of quality furnished by the supplier.

d. Source inspection, audit, and examination of items or services upon delivery or completion.

7.2.2 The TAC shall verify that items and services comply with procurement document technical and quality requirements. Quality conformance shall be documented on the appropriate forms.

7.2.3 Verification methods shall be appropriate to the requirements of the specific procured item or service and shall include one or more of the following:

a. Source evaluation and selection.

b. Receiving inspection.

c. Objective evidence of quality.

d. Source surveillance and audit.

e. Certificate of conformance.

\subsection{PROCUREMENT CONTROL}

7.3.1 Activities to control purchased materials, equipment, and services shall be established and implemented by written procedures. These procedures shall describe the methods used to evaluate contractor performance in meeting UMTRA Project objectives. The system for control of purchased materials, equipment, and services includes: 
a. Procurement planning.

b. Supplier selection.

c. Supplier performance evaluation.

d. Supplier-generated document control.

e. Acceptance of materials, equipment, and services.

f. Nonconformances.

\subsection{PROCUREMENT PLANNING}

7.4.1 Procurement planning shall determine what is to be accomplished, who is to accomplish it, and how and when it is to be accomplished. Planning shall include appropriate controls for the selection, determination of suitability, source evaluation and selection where determined necessary, and receipt of all purchased items. Planning shall be accomplished and documented as early as practicable to provide appropriate interface compatibility and to ensure a systematic approach to the procurement process.

7.4.2 Planning shall provide for the coordination of the following:

a. Procurement document preparation, review, and change control.

b. Selection of procurement sources.

c. Proposal or offer evaluation and award.

d. Evaluation of supplier performance.

e. Verification (surveillance, inspection, or audit) activities by purchaser, including notification for hold and witness points.

f. Control of nonconformances.

g. Corrective action.

h. Acceptance of materials, equipment, or services.

i. QA records.

\subsection{SUPPLIER SELECTION}

7.5.1 The TAC shall be responsible for soliciting offers or proposals, as well as evaluating prospective suppliers to ensure that only qualified suppliers are selected. The selection of suppliers shall be based on the supplier's capacity to 
provide items or services in accordance with procurement requirements prior to award of contract. The TAC Contracts Department shall maintain a current approved suppliers list (suppliers previously approved by TAC Procurement and QA), as appropriate. Methods for evaluating and selecting supplier sources, and the results obtained from these evaluations and selections, shall be documented and signed by the individuals performing the review. These methods include one or more of the following:

a. Evaluation of the supplier's history of providing an identical or similar product or service that performs satisfactorily in actual use. The supplier's history shall reflect their current capabilities and be supported by documentation.

b. Evaluation of the supplier's current quality records, supported by documented qualitative or quantitative information.

c. Preaward survey of the supplier's technical and quality capabilities as determined by a direct evaluation of the facilities, personnel, and implementation of the supplier's QA program.

\subsection{PROCUREMENT DOCUMENTS}

7.6.1 Procurement documents shall contain a statement of the scope of the work to be performed by the supplier; shall either reference or incorporate applicable technical and administrative requirements, such as specifications, codes, standards, tests, and inspections; and shall include acceptance criteria. As appropriate, requirements shall be included that the supplier have a documented QA program that implements applicable TAC QAPP requirements. Provisions shall include access to the supplier's plant facilities and records for inspection or audit by the TAC or parties authorized by the TAC. Procurement documents shall identify the documentation required for information, review, submittal time, evaluation against acceptance criteria, or TAC approval.

7.6.2 Procurement documents and changes thereto shall be prepared, reviewed, approved, issued, and controlled by the TAC Contracts Department. Personnel responsible for initiating the procurement requirement shall participate in the review and approval process to ensure that applicable requirements are incorporated in the procurement documents. Procurement documentation procedures shall include review methods for original documents, document revisions, and changes to ensure that documents transmitted to prospective suppliers include appropriate provisions ensuring that items or services meet specified Project requirements.

7.6.3 Reviews will verify the following for procurement documents:

a. They are prepared in accordance with applicable procedural requirements.

b. They reflect adequate and appropriate quality requirements. 
c. They include applicable regulatory design basis and related technical information, and state requirements properly.

\subsection{SUPPLIER PERFORMANCE EVALUATION}

7.7.1 Qualified suppliers and necessary subtier suppliers shall be monitored periodically by the TAC OA Department to ensure that acceptable items or services continue to be supplied. Source surveillance shall be performed as contractually required, or when the assembled condition of an item precludes adequate receiving inspection of important characteristics. These inspections and/or audits shall be performed in accordance with TAC SOPS.

7.7.2 The methods used shall include one or more of the following:

a. Establishment and evaluation of performance objectives.

b. Review of suppliers' records and nonconformance controls.

c. The performance of management reviews, audits, inspections, and surveillances.

7.7.3 The TAC organization receiving the item shall perform receiving inspections as required to verify conformance to procurement requirements. Receiving inspections shall be documented on the Purchase Order Form. Provisions shall be made for holding items pending receipt of required documentation. When possible, nonconforming items shall be held in a segregated area until satisfactory disposition is made.

7.7.4 Objective evidence of quality shall be required from suppliers in accordance with specifications listed in procurement documents. Examples of such evidence include:

a. Certificates of conformance.

b. Certificates of compliance.

c. Test reports with required serial number, lot number, or some other unique number.

d. Inspection reports.

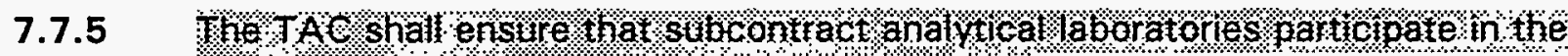
intertaboratory comparts on studes listed below

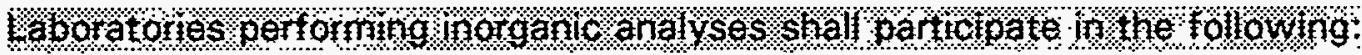

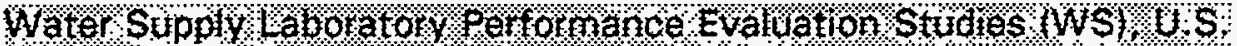

Environmental Protection Agency concinnat ono. 


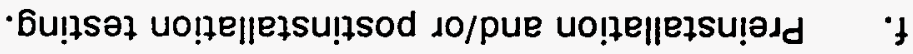

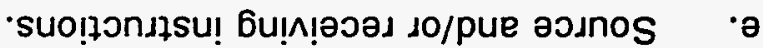

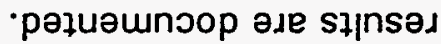

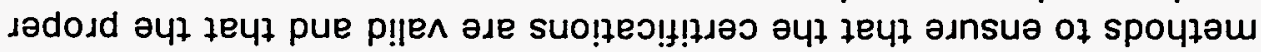

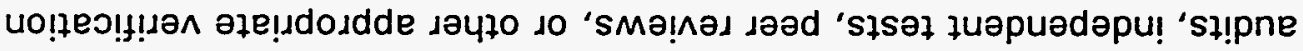

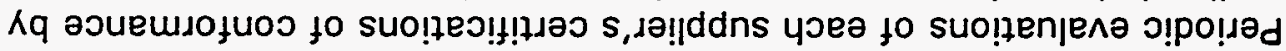

- słuəuəม!nbəd

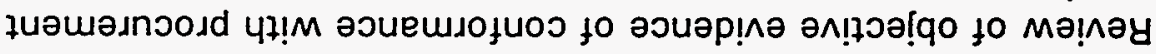

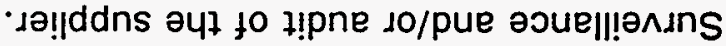

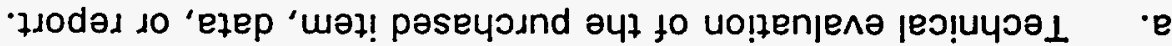

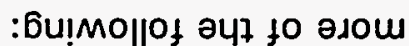

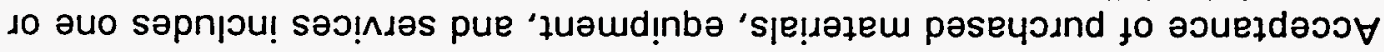

$1 \cdot 6 \cdot L$

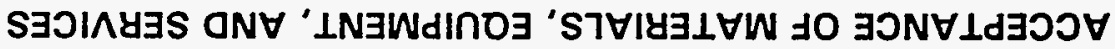

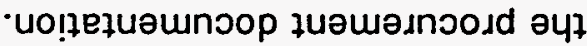

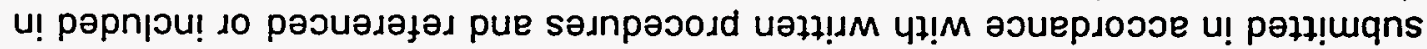

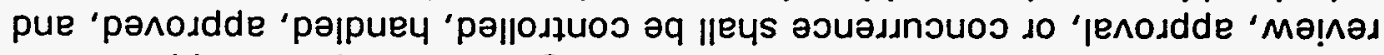

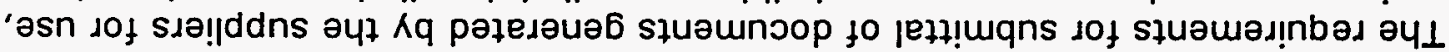

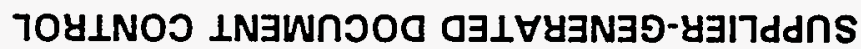

$8 \cdot L$

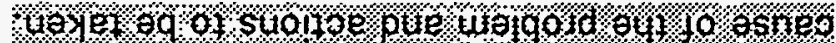

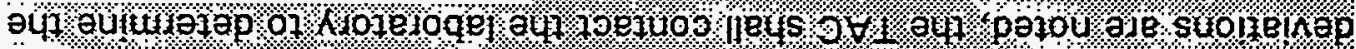

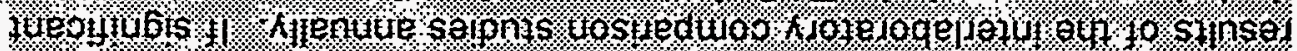

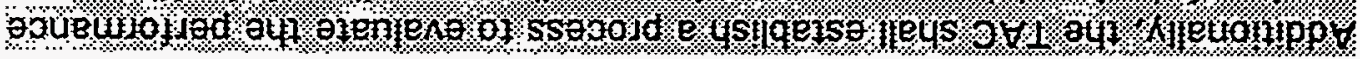

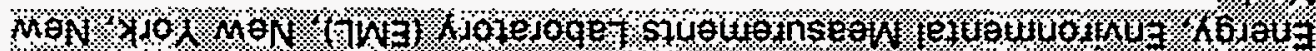

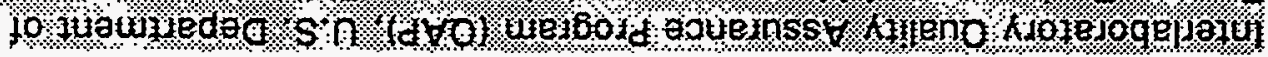

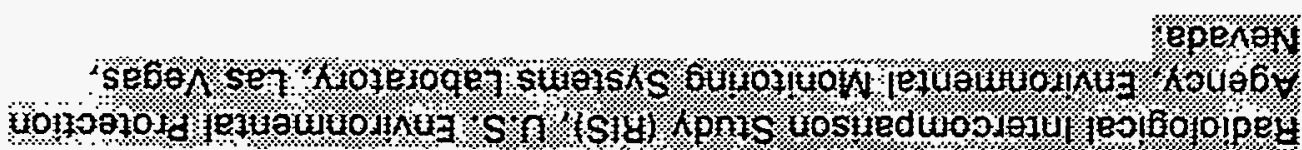

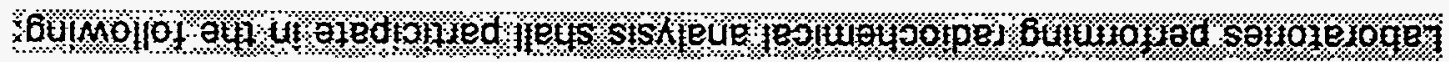

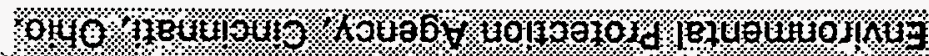

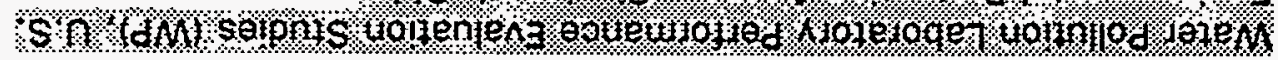


7.9.2 Before a procured item is placed in service, procurement specifications and inspection and test requirements shall be satisfied and nonconformances properly dispositioned in accordance with Section 3.0 of this QAPP.

7.9.3 The quality of purchased items and services shall be verified to a degree consistent with their complexity, risk, quantity, and frequency of procurement.

\subsection{NONCONFORMANCES}

7.10.1 Procurement documents shall include the TAC's requirements for reporting and approving disposition of nonconformances. Through written procedures, the TAC shall establish methods for disposition of items and services (in Section 3.0 of this QAPP) that do not meet procurement documentation requirements. These written procedures shall contain provisions for the evaluation of nonconforming items and submittal of nonconformance notice to the TAC by the supplier. These submittals shall include supplier-recommended disposition (e.g., use-as-is or repair) with technical justification; TAC's disposition of supplier recommendation; verification of the implementation of the disposition; and maintenance of records of supplier-submitted nonconformances.

\subsection{FRAUDULENT ACTIVITIES}

7.11.1 When there are indications that suppliers knowingly supplied items and services of substandard quality, this information shall be forwarded to the UMTRA Project Office.

\subsection{VERIFICATION}

7.12.1 The TAC QA Department shall periodically audit the control of purchased materials, equipment, and services to determine the degree of compliance with applicable Project requirements. 


\subsection{INSPECTION AND ACCEPTANCE TESTING}

\subsection{INSPECTION}

\subsubsection{Purpose}

a. This section describes the methods of inspection to verify conformance of an item or activity with specified requirements. Characteristics to be inspected and the methods to be employed shall be written, planned, and executed.

\subsubsection{General}

a. Both one-of-a-kind items and commercial items of hardware and equipment purchased to support the Project shall be subject to the inspection controls previously described. Indirect monitoring shall be applied as necessary to establish the adequacy of the item; personnel may not inspect their own work for acceptance. The level of inspection and degree of independence of inspection personnel should be based on risk and complexity.

b. Administrative controls and status indicators shall preclude inadvertently bypassing required inspections and prevent inadvertent operations of the item or process. The acceptance of items, materials, and processes shall be documented and approved by authorized personnel. When acceptance criteria are not met, deficiencies should be resolved and reinspection shall occur as required.

\subsubsection{Inspection procedures}

a. Inspection procedures shall be developed and approved for all planned levels of inspection and final acceptance.

b. Inspection procedures shall specify the characteristics to be inspected and methods to be followed to determine if an item, process, or service meets the technical and quality requirements. These procedures shall specify the inspection sequence, inspection and measurement equipment required, required prerequisites, inspection hold points, acceptance criteria, and documentation of inspection results. The inspection procedures, including any changes, shall be approved by the appropriate task manager.

c. These procedures require that inspections be performed by qualified personnel. Inspection personnel shall not report directly to the immediate supervisors who are responsible for performing the work being inspected. 


\subsubsection{Inspection personnel}

a. Inspectors shall be qualified through experience, training, and examination to perform all inspection services required.

b. Inspectors shall not report to the persons responsible for performing the work being inspected or to their supervisors.

\subsubsection{Receiving inspection}

a. Assigned inspectors will conduct a receiving inspection when equipment/materials are received on the site or at designated storage locations, using purchasing documents, drawings, specifications, and procedures.

b. A receiving report will be issued verifying acceptance or rejection.

c. Equipment/material not in compliance shall be handled and documented as described in Section 3.0 of this QAPP.

d. In the event of damaged equipment/material, the inspector shall coordinate findings with the procurement representative to assist in reducing delays and repair or replacement costs.

\subsubsection{Inspection records}

a. The OA Department shall be responsible for developing records and reports to adequately ensure that items meet all required specifications.

b. Inspectors shall be responsible for initiating records, reporting, and coordinating and maintaining the official $Q A$ files.

c. At a minimum, records shall identify conformance to specified requirements by evidence of systematic recording of the following:

1. Inspected item.

2. Inspection dates.

3. Inspectors making the inspections.

4. Type of observations and standards used.

5. Extent of acceptability.

6. Reference to information on action taken in connection with nonconformance. 


\subsection{ACCEPTANCE TESTING}

\subsubsection{Purpose}

a. This section specifies requirements for controlling acceptance testing to ensure compliance with Project requirements.

\subsubsection{General}

a. Tests required to verify conformance of an item to specified requirements and to demonstrate satisfactory performance shall be planned and executed. Characteristics to be tested, environmental sampling criteria, and test methods to be employed shall be specified.

b. The TAC shall ensure that such tests are performed in accordance with written test procedures which incorporate or reference the requirements and acceptance limits contained in applicable design documents.

c. The TAC shall ensure that required test results are documented and are reviewed by responsible personnel to ensure that test requirements have been met.

\subsubsection{Requirements}

a. Acceptance testing procedures, including those for field and laboratory environmental sampling, shall describe the methods for ensuring that tests are properly planned, executed, documented, and evaluated. Required tests shall be performed to verify conformance of an item to specified requirements, to demonstrate that items will perform satisfactorily in service, and to collect data (such as siting or design input). Testing shall include appropriate field and laboratory environmental sampling, bench and proof tests before installation, preoperational tests, postmaintenance tests, postmodification tests, and operational tests.

\subsubsection{Acceptance testing}

a. Testing may be implemented by or for the organization performing the work to be tested. However, personnel within the organization shall not. test their own work for acceptance. Qualification requirements for testing personnel shall be defined. Test procedures shall define the administrative controls and status indicators which shall preclude inadvertently bypassing required tests or operation of the item or process.

b. Testing shall be performed in accordance with written test procedures that incorporate or reference the performance requirements included in the design specifications or other procurement documents. 
c. Test procedures shall include sampling; test article configuration; instructions and prerequisites to perform the test; completeness and accuracy of data; acceptance criteria, including data verification; specific test equipment, including calibration requirements; suitable environmental conditions; testing hold points as required; and documentation of test results. Acceptance of items, materials, processes, and environmental sampling results shall be documented and approved by authorized personnel.

d. All activities involving the generation, acquisition, and use of environmental data shall be planned and documented. Procedures shall be established and implemented to perform inspections and acceptance testing (including the use of $Q C$ samples) of environmental sampling and measurement systems and their components according to the intended use of the items as specified by the design. The type and quality of environmental data needed for their intended use shall be defined and documented using the DQO process and shall involve key users of the data as well as those responsible for activities affecting data quality.

e. The data collection process for characterizing environmental processes and conditions shall be defined, controlled, verified, and documented. The data collection design process includes the design of field sampling events, sample handling and custody, analytical operations, data validation and verification methods, techniques for assessing limitations on data use, and data reporting requirements. The design process also applies to data compilation for modeling or additional studies.

f. In lieu of specially written test procedures, appropriate sections of applicable codes and standards can be used as acceptance requirements and test methods.

g. Retesting items or processes to determine if they meet acceptance criteria shall be required after deficiencies have been corrected.

\subsubsection{Test results}

a. Test results shall be documented and evaluated by qualified personnel to ensure that test requirements have been satisfied.

\subsubsection{Test records}

a. At a minimum, test records shall identify the following:

1. Item tested.

2. Date of test.

3. Tester or data recorder. 
4. Observations.

5. Results and acceptability.

6. Action taken in connection with any deviations noted.

7. Person evaluating the test results.

b. Test records shall be sent to appropriate Project files for proper storage and filing.

\subsection{MEASURING AND TEST EQUIPMENT}

\subsubsection{Purpose}

a. The purpose of this section is to establish a calibration system to ensure that all M\&TE used to verify conformance to specifications and drawing requirements are of the proper type, range, and accuracy, and are uniquely identified and traceable to their calibration test data.

\subsubsection{General}

a. A process shall be established and implemented to control calibration, maintenance, and accountability for tools, gages, instruments, and other M\&TE used for activities affecting quality. To maintain accuracy within necessary limits, the M\&TE shall be controlled and at specified periods calibrated and adjusted.

b. The TAC shall ensure that a scheduled system of retesting, adjusting, and recalibration is maintained and documented to ensure required accuracy commensurate with the importance of the equipment.

c. Testing laboratories and subcontractors that calibrate M\&TE shall have a calibration system that complies with Project requirements. When contractually responsible, the TAC shall review testing laboratory subcontractor systems to ensure satisfactory programs. Testing laboratories/subcontractors shall verify compliance with their calibration procedures.

\subsubsection{Requirements}

a. The TAC shall utilize M\&TE which is of the range and accuracy adequate to determine product conformance to design requirements. M\&TE that is of special design for a particular activity shall be designed, developed, and manufactured or procured under TAC control. Before such equipment is used, a complete functional check shall be conducted according to written procedures to ensure conformance to specifications and to ensure that the equipment is properly calibrated. 
b. Written procedures for calibrating specific M\&TE shall be provided to ensure that calibration requirements are identified and followed.

c. M\&TE shall be calibrated and maintained at specified intervals in accordance with approved procedures on the basis of the item's required accuracy, intended use, frequency of use, stability characteristics, and other conditions affecting its performance.

d. M\&TE shall be labeled, tagged, or otherwise controlled to indicate its calibration status and ensure traceability to calibration test data.

e. M\&TE found out of calibration or out of tolerance shall be tagged and/or segregated and not used until it is successfully recalibrated. The acceptability of items or processes measured, inspected, or tested with an out-of-tolerance device shall be evaluated.

\subsubsection{Procedure}

\section{a. Calibration of M\&TE}

1. All M\&TE requiring calibration shall be identified by a serial number or a control identification number.

2. All M\&TE requiring calibration shall have a calibration tag or sticker affixed in a conspicuous location to readily identify the calibration status of the instrument. Typical information on the calibration tag or sticker are the calibration date, instrument serial number, next calibration date, and the name of the person who calibrated the instrument.

3. Calibration records and schedules shall be maintained for each item of equipment requiring calibration.

4. A record of all equipment requiring calibration, including a maintenance schedule, shall be maintained. Maintenance shall be accomplished in accordance with approved procedures.

5. Should the accuracy of any instrument be questioned, it shall be tagged as such and shall be recalibrated before reuse.

\subsubsection{Calibration standards}

a. M\&TE requiring calibration shall be calibrated against measurement standards that will ensure the equipment will be within required tolerances. The calibration standards shall be traceable to nationally recognized calibration standards. Calibration shall be performed only by properly qualified personnel. Certificates shall be maintained attesting to the date and accuracy of the results. 


\subsubsection{Issuance of M\&TE}

a. Before issuance of M\&TE, the responsible individual shall check and then log out the equipment. Upon return of the issued equipment, the responsible individual shall note the return and condition of the equipment.

\subsection{VERIFICATION OF IMPLEMENTATION}

a. The TAC QA Department shall audit the inspection, acceptance testing, and M\&TE calibration control program to ensure compliance with approved procedures. 


\subsection{MANAGEMENT ASSESSMENTS}

\section{$9.1 \quad$ PURPOSE}

9.1.1 This section describes management assessments that shall be used to analyze the degree of compliance, integration, performance, and adequacy of the TAC QA program.

\subsection{GENERAL}

9.2.1 Management assessments shall focus on how well the integrated QA program is working, and shall determine if problems exist that hinder the TAC from achieving its objectives in accordance with quality, safety, and environmental requirements. These assessments shall be established and implemented to improve quality within the TAC.

\subsection{REQUIREMENTS}

9.3.1 Annual management assessments shall provide a means for determining and taking necessary response actions regarding the following:

a. Effectiveness of the system of management controls that are established to achieve and ensure quality.

b. Adequacy of resources and personnel provided to achieve and ensure quality in all activities.

9.3.2 Senior management shall retain overall responsibility for these management assessments. Direct participation (by the manager or managers responsible for mission accomplishment and overall operations) is essential. This process shall include the direct participation of all appropriate levels of management. As deemed appropriate, assessments of designated organizations and programs may include the participation of qualified internal staff or independent reviewers.

\subsection{ASSESSMENT PURPOSE/RESULTS}

9.4.1 The results of the assessment shall be documented. Senior management shall. take prompt action and document decisions in response to recommendations resulting from the management assessment process. Follow-up reviews for recommendations shall include an evaluation of the effectiveness of management's actions.

\subsection{VERIFICATION}

9.5.1 The TAC QA Department shall evaluate these assessment activities to ensure compliance with the above requirements. 


\subsection{INDEPENDENT ASSESSMENTS}

\subsection{PURPOSE}

10.1.1 This section provides a means for establishing and implementing independent assessments.

10.2 GENERAL

10.2.1 A process of planned independent assessments shall be established and implemented by the TAC. Independent assessments shall focus on improving activities and processes by emphasizing the organization's achievement of quality. Independent assessments shall consist of reviewing, inspecting, testing, checking, conducting surveillances, sonductng wo dependent techrical rewews (TR) auditing, conducting preawardaudits, or otherwise determining and documenting whether items, processes, or services meet specified requirements.

10.2.2 The TAC assessment program shall consist of a comprehensive system of planned assessments that verifies compliance with program requirements and determines the program's continuing effectiveness.

10.2.3 Internal assessments shall include all TAC activities; external audits shall audit: Tho review the activities of suppliers and contractors outside the TAC. Extenal audits rnay incuude preawardaudits.

10.2.4 The TAC QA and Regulatory Compliance Departments shall provide support for the UMTRA Project Office independent assessments of the RAC and active remedial action sites.

\subsection{REQUIREMENTS}

10.3.1 Independent assessments shall be conducted to determine the degree of compliance to UMTRA Project requirements and approved procedures. Independent assessments shall be conducted on all remediation activities conducted at processing sites, disposal cells, or vicinity properties. Vicinity property independent assessments shall be dependent upon remediation activities in progress during site visits. With concurrence from the DOE UMTRA Project Office, all independent assessments may include disciplines, such as health and safety, radiology, and environmental specialists to assist during these activities. Documented assessment results shall provide the respective managers an independent technical and/or programmatic evaluation of their activities.

10.3.2 Quality-related independent assessments, audits, preaward audits, TRs, or inprocess surveillances of TAC operations shall be conducted by a lead auditor who meets the qualifications described in the TAC SOPs. Independent 
assessments which address various disciplines (i.e., administration, planning, scheduling, procurement contracts, cost/scheduling, environment, safety, and the like), shall be conducted by personnel qualified in these disciplines who have experience in conducting independent assessments.

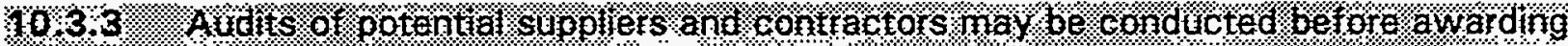

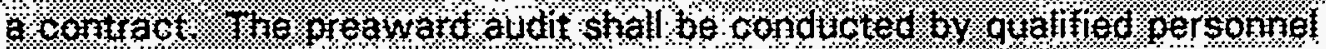
krowledgeable $n$ he supplien contractor prodfet and activities:

10.3.4 The lead auditors that support the UMTRA Project Office for the TAC and active remedial action sites shall meet the requirements outlined in Section 10.5.2 of this document.

10.3.5 Independent assessments shall be conducted in accordance with TAC SOPS. Personnel performing these independent assessments shall act in a management advisory function. Their responsibilities are to 1) monitor work performance using criteria that describe acceptable performance; 2) identify satisfactory and abnormal performance and potential problems; 3) identify opportunities for improvement; 4) report results to a level of management having the authority to effect corrective action, and 5) verify satisfactory resolution of the corrective action. The personnel performing these independent assessments shall be qualified and knowledgeable about the activity being assessed, shall focus on improving the quality of the activity, and shall not have direct responsibilities in the area they are assessing.

\subsection{SCHEDULING}

10.4.1 Scheduling these assessments and allocating of resources shall be based on the status, risk, and complexity of the activity or process being assessed.

Scheduling shall be flexible. Areas of questionable performance shall be addressed. Organizational activities may be assessed several times a year or at longer intervals, depending on the activity or the quality aspects of the activity.

10.4.2 In support of the UMTRA Project Office audit activities, the TAC QA Department shall be responsible for developing and tracking each fiscal year $Q A$ audit/surveillance schedules. This includes audits and surveillances of TAC operations and RAC and active remedial action sites. The audit/surveillance schedules for the RAC and active remedial action sites shall be submitted to the respective UMTRA Project Office, RAC, and TAC organizations. Additional audits/surveillances shall be conducted on an unannounced basis as directed by the UMTRA Project Office. The audit/surveillance schedule will be reviewed monthly or at the discretion of the UMTRA Project Office, depending on Project activity, and revised accordingly to ensure that schedules are kept current. The audit/surveillance schedule for the TAC operations will be updated monthly.

10.4.3 For UMTRA Project Office audit activities, a maximum of two concurrent audits shall be held at the RAC or an active remedial action site. 


\subsection{AUDIT PERSONNEL}

10.5.1 A lead auditor will be selected and assigned for each audit activity.

10.5.2 For UMTRA Project Office audits a lead auditor for quality-related, environment, health, and safety (EH\&S), and radiological audits will be selected and assigned for each activity. Prior approval of lead auditors shall be obtained from the UMTRA Project Office QA manager or Technical Support Group leader (TSGL). To qualify as a lead auditor on the UMTRA Project, an individual shall participate in a minimum of five hands-on audits under the supervision of a qualified lead auditor. However, two of the five audits shall have been UMTRA-site related.

10.5.3 The UMTRA Project Office QA manager or TSGL may grant an exception to the above requirements based on the individual's education, special training, and experience (including audit experience). Such information shall be documented and provided for UMTRA Project Office approval.

10.5.4 Health and safety, environmental, and radiological supervisors shall submit a lead auditor candidate(s) resume and audit experience to the TAC QA Department after the individual(s) have participated in the minimum required audits outlined in paragraph 10.5.2. The TAC OA Department shall submit the proposed lead auditor(s) name and associated documentation to the UMTRA Project Office for review and approval. This list shall be maintained and updated as required by the TAC QA Department. The documentation shall contain but not be limited to the following:

a. Name.

b. Number and description of total audits and associated time frames.

c. Number of UMTRA-related audits.

d. Education.

e. Experience.

f. Specialized training completed during the past 2 years.

10.5.5 For both TAC-related and UMTRA Project Office audit activities the lead auditor may select appropriate additional audit team members. When required, the lead auditor may use expertise of specialists in specific areas.

10.5.6 Approval shall be obtained from the UMTRA Project Office OA manager or TSGL before the specialist assists in any audit. The TAC QA Department shall develop and maintain a list of specialists, and their resumes, and submit it to the UMTRA Project Office for approval as required. 
10.5.7 Maintenance of qualification and proficiency of lead auditors shall be accomplished through one or more of the following: regular and active participation in the audit process; review and study of codes, standards, procedures, instructions, and other documents related to the QA program and program auditing; and participation in training program(s). Requalifications of lead auditors who fail to maintain their proficiency for a period of 2 years or more shall require requalification as outlined in paragraph 10.5.2.

\subsection{PREAWARD EVALUATION}

10.6.1 A preaward audit shall be conducted to determine a prospective vendor's ability to meet the engineering and $\mathrm{QA}$ requirements of TAC procurement documents. Such an evaluation shall be performed and documented before the award of a purchase order or subcontract.

\subsection{VENDOR AUDIT}

10.7.1 A TAC vendor audit is a QA evaluation of a vendor after the award of a purchase order. Major findings revealed during an audit of any analytical audit shall be reported to the UMTRA Project Office.

\subsection{INTERNAL AUDIT}

10.8.1 An internal audit is a QA evaluation of TAC departments and organizations that affect the overall TAC operations. A minimum of one audit a year will be conducted on each organization.

\subsection{UMTRA PROJECT OFFICE AUDITS}

10.9.1 An UMTRA Project Office audit is a QA evaluation conducted by the UMTRA QA manager or TSGL and assisted by the TAC QA Department of UMTRA Project Office contractors' and subcontractors' site functions. Site audits are conducted annually or at least once during the life of activity, whichever is more frequent.

\subsection{TAC SUPPLEMENTAL AUDITS}

10.10.1 A supplemental audit may be conducted as directed by the TAC QA manager. These audits may be conducted for one or more of the following reasons:

a. When it is reasonably suspected that the safety, performance, or reliability of the equipment, material, or service is inadequate.

b. When a systematic assessment of the QA program is considered necessary.

c. To verify implementation of corrective action. 
d. When significant changes are made in the functional areas of internal operations under the vendor's QA program.

\subsection{AUDIT PREPARATIONS}

10.11.1 Audit preparations shall include the following:
a. Audit assignment (selection of a lead auditor).
b. Audit team selection.
c. Planning meeting and the development and preparation of an audit checklist.

d. Notification to the audited organization.

10.11.2 At least 3 days in advance of the independent assessment being conducted for the UMTRA Project Office, the TAC will furnish the DOE with a list of auditors by name, designating the lead auditor for each team, a checklist for each audit team, and any items that will receive special attention during the independent assessments.

\subsection{AUDIT PERFORMANCE}

10.12.1 Audits are initiated by the TAC QA manager, the UMTRA Project Office QA manager, and the UMTRA Project Office TSGL. Audits will be performed in accordance with written procedures or checklists. Audit performance for announced audits will include a notification letter to the organization being audited, a preaudit meeting, audit activity, and a postaudit meeting, followed by a documented evaluation of activity compliance, corrective actions, required follow-up, and closeout. For the UMTRA Project Office audits a DOE representative shall be in attendance at the audit opening and exit meetings. However, DOE attendance at the audit opening meeting may be waived by the UMTRA Project Office QA manager or TSGL.

10.12.2 Elements that have been selected for the audit will be evaluated against specified approved requirements. Documented and physical objective evidence will be examined to a depth necessary to determine if activities are being conducted in accordance with prescribed and approved requirements and procedures.

10.12.3 Any condition found during the audit that requires immediate corrective action shall be documented and reported promptly to the management of the organization being audited.

10.12.4 The audit teams shall inspect all findings and observations of the previous audit and ensure they have been corrected and satisfactorily incorporated. If corrective actions have not been implemented for all of the findings and 
observations, the audit team shall promptly notify the appropriate site management and the UMTRA Project Office. The review of previous observations and findings shall be documented in the audit report as will the new findings.

10.12.5 For UMTRA Project Office audits, the DOE representative and the audit team shall, at the conclusion of each day's activities, meet and brief the Project contractor's staff on the audit team's findings and observations for that day. All findings and observations, regardless of their magnitude, shall be presented at these debriefings.

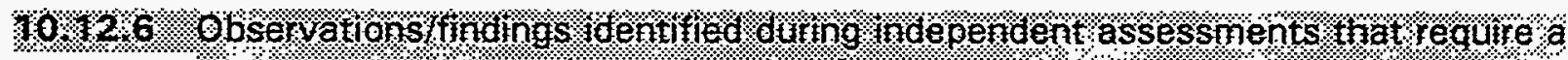

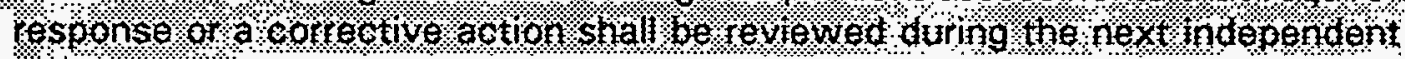
assessinent:

\subsection{AUDIT REPORT}

10.13.1 The audit report shall be prepared and signed by the lead auditor and team members and transmitted to the manager of the organization that was audited for action, as appropriate. For UMTRA Project Office audits, the report shall be provided to the respective UMTRA OA manager or TSGL for transmittal to the appropriate management organization. All findings and observations shall be noted in the final audit report, regardless of magnitude or whether or not they were corrected immediately.

10.13.2 The report will include but not be limited to the following information:
a. Audited organization.
b. Audit date.
c. Team members.
d. Organization's personnel contacted.
e. Summary of results.
f. Criteria references.
g. Observations.
h. Recommendations (if applicable).

10.13.3 Audit reports shall be issued within 10 working days from the conclusion of the audit. Audit transmittal memos shall require that the audited organization perform a root-cause analysis for each observation or finding that requires a response. 
10.14 AUDIT RESULTS/RESPONSE

10.14.1 The audited organization shall be responsible for determining the corrective actions for each observation of nonconformance. The audit results/response shall be tracked and resolved by management having responsibility in the area audited. The responses to the results of the audits shall be provided to the QA manager and shall include, as applicable, 1) cause identification, 2) action to correct the deficiency, and 3 ) actions to prevent recurrence.

10.14.2 For QA, EH\&S, and radiological audits performed for the UMTRA Project Office, the appropriate TAC Department shall, at the request of the UMTRA Project Office, review proposed corrective actions to ensure that adverse conditions have been adequately addressed and corrected. A follow-up audit may also be required by the UMTRA Project Office if significant corrective action is necessary or to verify implementation of proposed corrective action.

10.14.3 The review of the response to the audit report includes:

a. Review of the corrective action taken to ensure that it resolved the observation and recommendation.

b. Verification that any necessary corrective action is being accomplished.

c. If closeout is possible, verification that all pertinent documents are in the audit file. If closeout is not justified, verification will take place upon satisfactory completion of corrective actions.

d. Assessment of the verification report (when applicable) to determine if information is thorough enough to permit audit closeout.

\subsection{FOLLOW-UP AUDITS}

10.15.1 Follow-up audits may be performed to verify whether corrective action is accomplished and precludes recurrence of adverse conditions.

\subsection{FAILURE TO RESPOND}

10.16.1 For TAC QA audits, if the audited organization fails to respond by a specified date, the OA manager or lead auditor shall contact the audited organization and obtain justification for the delay. If the response time is extended, it shall be documented in the audit file. 


\subsection{REFERENCES}

DOE (U.S. Department of Energy), 199\%a. UMTRA Project Office Quality Assurance

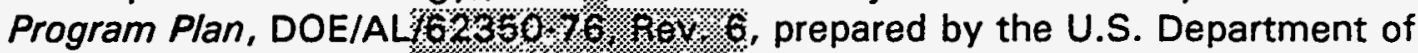
Energy, UMTRA Project Office, Albuquerque Operations Office, Albuquerque, New Mexico.

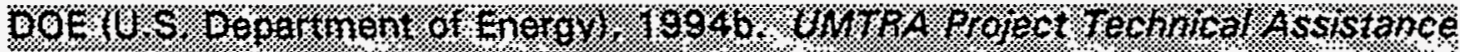

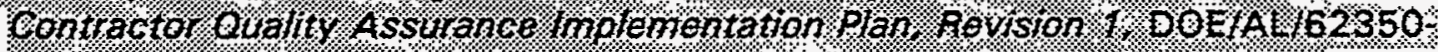

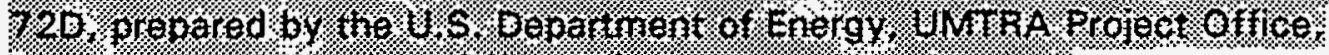

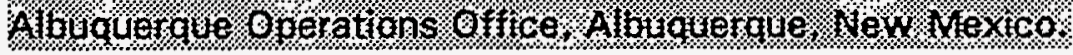

DOE (U.S. Department of Energy), 199\%c. UMTRA Project Document Control System Manual, DOE/AL 6235098 , prepared by the U.S. Department of Energy, UMTRA Project Office, Albuquerque Operations Office, Albuquerque, New Mexico.

DOE (U.S. Department of Energy), 1992. Software Program for Environmental Analysis and Reporting (SPEAR) System, U.S. Department of Energy, UMTRA Project Office, Albuquerque Operations Office, Albuquerque, New Mexico.

\section{DOE ORDERS}

Order 1324.2A, Records Disposition, prepared by the U.S. Department of Energy, Washington, D.C.

Order 5700.6C, Quality Assurance, August 21, 1992, Office of Nuclear Energy and Office of Environment Safety, and Health, U.S. Department of Energy, Washington, D.C. 


\subsection{GLOSSARY}

Acceptance Criteria

Adverse to Quality

Audit

Certificate of Compliance

Certificate of Conformance

Certification

Characteristic

Code

Conditions

Corrective Action

Deficiency
Specified limits placed on characteristics of an item, process, or service defined in codes, standards, or other requirement documents.

A significant condition adverse to quality is one which, if uncorrected, could have a serious effect on safety or operability.

A planned and documented activity performed to determine by investigation, examination, or evaluation of objective evidence the adequacy of and compliance with established procedures, instructions, drawings, and other applicable documents, and the effectiveness of implementation. An audit should not be confused with surveillance or inspection activities performed for the sole purpose of process control or product acceptance.

A document signed by an authorized party affirming that the supplier of a product or service has met the requirements of the relevant specifications, contract, or regulations.

A document signed by an authorized individual certifying the degree to which items or services meet specified requirements.

The procedure and action by a duly authorized person of determining, verifying, and attesting in writing to the qualifications of personnel, processes, procedures, or items in accordance with applicable requirements.

Any property or attribute of an item, process, or service that is distinct, describable, and measurable.

A recognized national standard of manufacture, assembly, or test referenced by engineering specifications or drawings.

An all-inclusive term used in reference to any of the following: failures, malfunctions, deficiencies, defective items, and conformances.

Measures taken to rectify conditions adverse to quality and, where necessary, to preclude repetition.

A nonconformance of a minor nature. Deficiencies are not directly associated with the structural integrity of an item, but do constitute a violation of Project procedural requirements. 
Design Change

Design Criteria

Design Documents

Design Group

Design Review

Deviation

Document

Examination

External Audit

Guideline
A revision to a drawing, specification, procedure, or other design document which has been released, or supports a design document which has been released, for manufacture, fabrication, or construction.

Applicable code, regulatory, industrial, or client requirements, including standards for design work which must be satisfied by design documents.

Drawings, specifications, calculations, records, reports, and other documents which may be used for design, manufacture, fabrication, installation, testing, examination, and certification of items.

Any group that uses design criteria to generate design documents.

The formal review of an existing or proposed design for the purpose of detection and remedy of design deficiencies which could affect fitness-for-use and environmental aspects of the product, process, or service; and/or identification of potential improvements of performance, safety, and economic aspects.

A departure from specified requirements.

Any written or pictorial information describing, defining, specifying, or certifying activities, requirements, procedures, or results.

An element of inspection consisting of investigation of items or services to determine conformance to those specified requirements which can be determined by such investigation.

A systematic examination of the acts and decisions of another organization with respect to quality, in order to independently verify or evaluate compliance to the operational requirements of the quality program, for compliance to specification or contract requirements of the product or service.

A suggested practice that is not mandatory in programs intended to comply with a standard. The word should denotes a guideline; the word shall denotes a requirement. 
Hold Point

Identification

Inspection

Inspector

Internal Audit

Item

Material

Measuring and Test

Equipment (M\&TE)

Nonconformance
Term used to refer to an examination, test, or special process which must be performed by the Inspector to measure a characteristic and verify its conformance to the acceptance criteria. Hold points include "Mandatory Hold Points" and other hold points needed to verify conformance.

A controlled serial number, lot number, data code, or combined serial and lot number or data code which relates the item, assembly, model, or system to a particular lot of raw material, process, manufacturing data, cure date, receiving date, purchased lot, historical record, inspection or test data, calibration data, assembly process, matched articles, expiration date, operating time, $X$-ray, or other pertinent data.

The process of measuring, examining, testing, gaging, or otherwise comparing the product or service with the applicable requirements.

A person who performs inspection activities to verify conformance to specific requirements.

An audit of those portions of an organization's $Q A$ program retained under its direct control and within its organizational structure.

An all-inclusive term used in place of any of the following; appurtenance, assembly, component, equipment, material, module, part, structure, subassembly, subsystem, system, or unit.

A substance or combination of substances forming components, parts, pieces, or equipment lintended to include machinery, castings, liquids, formed steel shapes, aggregates, cement, and the like).

Devices or systems used to calibrate, measure, gage, test, or inspect in order to control or to acquire data to verify conformance to specified requirements.

A variance from contractual requirements which adversely affects safety, durability, performance, interchangeability of parts or assemblies, weight (where weight is a significant consideration), or any other basic objective of the specification. 
Nondestructive Examination (NDE)

Objective Evidence

Owner

Procedure

Procurement Documents

Purchasing

Qualification

Qualified Procedure

Quality Assurance (QA)

Quality Assurance Program

Quality Assurance Program Audit

Quality Assurance Record
Methods of detection or measurement of properties or performance capabilities of materials, items, or structures which do not impair their serviceability. These include, but are not limited to, the following: radiography, ultrasonic, liquid penetrant, and magnetic particle.

Any documented statement of fact, other information, or record, either quantitative or qualitative, pertaining to the quality of an item or service, based on observations, measurements, or tests which can be verified.

The person, group, company, agency, or corporation who has or will have title to a facility.

A document that specifies or describes how an activity is to be performed.

Purchase requisitions, purchase orders, drawings, contracts, specifications, or instructions used to define requirements for purchase.

The organization responsible for establishing procurement requirements and for issuing and administering procurement documents.

The characteristics or abilities gained through (personnel) education, training, or experience, as measured against established requirements, such as standards or tests, that qualify an individual to perform a required function.

An approved procedure that has been demonstrated to meet the specified requirements for its intended purpose.

All those planned and systematic actions necessary to provide adequate confidence that a product or service will satisfy given needs.

Those actions specifically established to integrate in documented form all of the administrative and technical quality-related activities required and effectively implemented by an organization to meet specified quality.

A documented activity performed to verify by examination and evaluation of objective evidence that applicable elements of the QA program are suitable and have been developed, documented, and effectively implemented in accordance with specified requirements.

A completed document that furnishes evidence of the quality of items and/or activities affecting quality. 
Quality Control (OC)

Receiving Inspection

Repair

Rework

Right-of-Access

Service

Special Process

Specification

Storage

Subcontractor

Supplier
The operational techniques and the activities which sustain a quality of product or service that will satisfy given needs; also, the use of such techniques and activities.

The process of receiving materials and supplier-fabricated parts, components, appurtenances, and equipment, and verifying by inspection and/or document reviews that the items conform to the design and procuring documents.

The process of restoring a nonconforming characteristic to a condition such that the capability of an item to function reliably and safely is unimpaired, even though that item still does not conform to the original requirement.

The process by which a nonconforming item is made to conform to a prior specified requirement by completion, remachining, reassembling, or other corrective means.

The right of a purchaser or designated representative to enter the premises of a supplier for the purpose of inspection, surveillance, or OA audit.

The performance of activities such as design, fabrication, inspection, nondestructive examination, repair, or installation.

A process, the results of which are highly dependent on the control of the process or the skill of the operators (or both), in which the specified quality cannot be readily determined by inspection or test of the product.

A concise statement of a set of requirements to be satisfied by a product, material, or process indicating, whenever appropriate, the procedure by which it may be determined whether the requirements are satisfied.

The controlled act of holding items at the construction site or in an area other than its permanent location.

Any organization under subcontract to furnish items or services. It includes the terms vendor, supplier, and fabricator and subtier levels of these where appropriate.

Any individual or organization who furnishes items or services to a procurement document. An all-inclusive term used in place of any of the following: vendor, seller, contractor, subcontractor, fabricator, consultant, and subtier levels. 
Surveillance

Survey

Testing

Traceability (calibration sense)

Traceability (data sense)

Use-As-Is

Verification

Waiver
A documented review, observation, or inspection performed by qualified QA personnel for the purpose of verifying that applicable quality requirements are accomplished as specified for engineering, procurement, manufacturing, construction, and installation where these activities occur.

An evaluation performed at a supplier's facilities prior to an award of a contract for the purpose of determining that the supplier has the ability to furnish services, materials, or factory QA program which meets code requirements.

A process of verification to determine the capability of an item to meet specified requirements by subjecting the item to a set of physical, chemical, environment, or operating conditions.

The ability to trace the calibration of measuring or testing equipment to a national standard, a recognized primary standard, or basic physical constraints or properties, usually through a series of calibrations of intermediate level standards.

The ability to trace the operational, computational, and recording steps of a measurement or evaluation of an item, process, or service.

A disposition permitted for a nonconforming item when it can be established that the item is satisfactory for its intended use.

The act of reviewing, inspecting, testing, checking, auditing, or otherwise determining and documenting whether items, processes, services, or documents conform to specified requirements.

Documented authorization to depart from specified requirements. 